
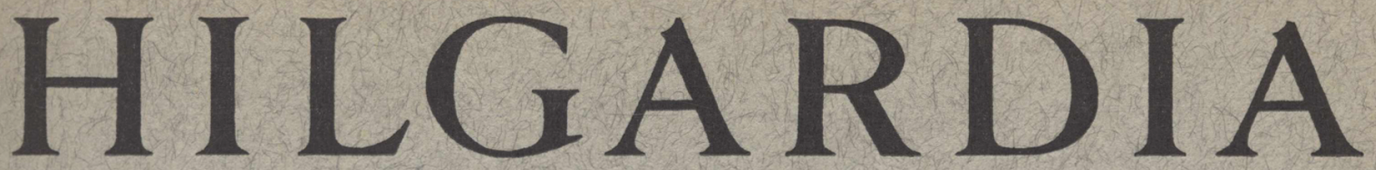

A Journal of Agricultural Science Published by the California Agricultural Experiment Station

\title{
EFFECT OF VARIOUS MAINTAINED LEVELS OF PHOSPHATE ON THE GROWTH, YIELD, COMPOSITION, AND QUALITY OF WASHINGTON NAVEL ORANGES
}

H. D. CHAPMAN and D. S. RAYNER 


\title{
EFFECT OF VARIOUS MAINTAINED LEVELS OF PHOSPHATE ON THE GROWTH, YIELD, COMPOSITION, AND QUALITY OF WASHINGTON NAVEL ORANGES ${ }^{1,3}$
}

\author{
H. D. CHAPMAN ${ }^{3}$ and D. S. RAYNER
}

\section{INTRODUCTION}

THIS PAPER presents the results of an outdoor nutritional experiment carried on for nine years with Washington Navel orange trees growing in solutions of graded phosphate levels.

The objective of this investigation was to determine as completely as possible the effects of varying phosphate supplies on : (1) a wide range of fruit quality characteristics; (2) yield behavior; (3) growth and appearance; and (4) tissue composition with special reference to the diagnosis of phosphorus status.

\section{REVIEW OF LITERATURE}

Much information relating to various aspects of phosphorus as it affects citrus has gradually accumulated from the work of scattered individuals or groups in different parts of the world. At the time the work reported in this paper was undertaken there was no adequate understanding of the problem. It is rather amazing, considering the radically different condition of water culture employed in the present experiment, that practically all the observations and data reported by others working under the variable soil and climatic conditions prevailing in the world's citrus regions have been duplicated and substantiated. Because these scattered data are an important contribution, and substantiate our present knowledge of this subject, a rather detailed account of previous experiments and findings is presented herewith.

So far as the authors know, no one has hitherto carried on a phosphate nutritional experiment of such scope and duration as that reported herein.

The only other water culture investigation on phosphorus as related to citrus known to the authors is that reported by Haas (1936). ${ }^{5}$ He grew lemon cuttings in solution cultures lacking phosphorus, and also young Valencia oranges in minus-phosphorus sand cultures, and found that a deficiency of

\footnotetext{
${ }^{1}$ Received for publication March 28, 1950.

2 Paper No.651, University of California Citrus Experiment Station, Riverside, California.

${ }^{3}$ Professor of Soils and Plant Nutrition and Chemist in the Experiment Station.

4 Senior Laboratory Technician, Citrus Experiment Station.

"See "Literature Cited" for citations, referred to in the text by author and date.
} 
this element caused the older leaves to turn a brownish green color and fall off prematurely. Many such leaves developed necrotic areas on the margins or tips. Phosphorus-deficient leaves showed values ranging between .04 to .07 per cent phosphorus in the dry matter.

Subsequently, Chapman and Brown (1941) described the effects of acute phosphorus deficiency on the fruit, foliage, and composition of navel orange trees growing in soil. The foliage symptoms were similar to those reported by Haas. The fruit produced on the phosphorus-deficient trees was rather coarse, of thicker rinds, and had a lower juice content than fruit from trees well supplied with this element. The acid was higher, but total solids in the juice were not measurably affected. Analyses of various parts of healthy and phosphorus-deficient trees showed very low levels of phosphorus in all parts of the plant except the young leaves. The old leaves of the phosphorus-deficient trees contained .05 per cent total phosphorus as compared with .11 per cent in healthy trees. Nitrogen, potassium, and magnesium were higher in the phosphorus-deficient leaves but calcium was lower.

A progress report on the present experiment, describing some of the effects of phosphorus lack on fruit, was published several years ago by Chapman, Brown, and Liebig (1943). The fruit from the low and phosphate-deficient trees was rather coarse textured and some of it was misshapen. It also lacked firmness, had hollow center tendencies, the rind was thicker, and juice percentage lower than in fruit from trees receiving adequate phosphate.

In connection with field fertilizer experiments carried on in different parts of the world, various observations and data as stated relative to phosphorus effects have been noted. In California, Jones and Parker (1949) found that fruit from Washington Navel orange trees that had been fertilized with phosphorus for over 20 years had a slightly higher juice content and lower ascorbic and total acid content than did that from trees fertilized only with nitrogen or nitrogen and potassium. No yield responses from phosphorus were obtained in this experiment (Parker and Batchelor, 1942), and the quality differences in general were considered to be of doubtful commercial importance. Finch and McGeorge (1945), in a grapefruit fertilizer experiment carried on for seven years in Arizona, got no increases in yield from phosphate or potash, and the quality and maturity of fruit from this experiment, as reported by Hilgeman (1941), were not affected by phosphorus fertilization. In tests of citrus fruit from Florida orchards fertilized with varying amounts of potash and phosphate, Collison (1913) found that fruit from the high potash orchards tested a little higher in acidity than did the fruit from orchards receiving little potash. However, in the case of phosphate, no significant differences in either acid or sugar were found.

Subsequently, Forsee and Neller (1944), reporting on a Valencia orange fertilizer experiment located on an acid peat soil in Florida, stated that definite yield, tree, and quality responses were obtained from the use of phosphate. The trees of plots that received a 3-0-12 fertilizer as compared with those receiving a 3-6-12 and a 3-12-12 fertilizer were smaller and made less vegetative growth. The leaves were smaller and somewhat narrow. The fruit was coarse, soft, had a brighter orange color, thicker rinds, and much of it was misshapen. The interior structure of the fruit was coarse and the juice more 
sour. Brix was somewhat higher in the no-phosphorus fruit, and there was a much greater preharvest drop. The high-phosphate treatment produced a greater per cent of ammoniation (copper deficiency in the fruit). Total phosphorus in the leaves from the phosphorus-deficient trees was .162 per cent as compared with .225 per cent in trees receiving a 3-12-12 fertilizer. In the fruit juice, the phosphorus content was 2.04 compared with 7.94 parts per million, and in the soil, an acid extractant showed 8 versus 94 pounds phosphorus per acre for the two plots. A more recent account of this work is given by Young and Forsee (1949).

Smith, Reuther, and Gardner (1949) checked the effects of several levels of phosphate fertilization on fruit size, rind thickness, percentage juice, soluble solids, acidity, ascorbic acid, and the N, P, K, Ca, and Mg in the juice of oranges from a field fertilizer trial. This experiment was on a sandy soil of Florida, and no yield effects were produced by the phosphorus. Of the various fruit characteristics checked in 1947 and again in 1948, it was found that soluble solids, citric acid, and ascorbic acid were lowered, but that no other characteristic was changed to an appreciable extent. Phosphorus and nitrogen in the juice were slightly increased by the phosphate fertilizer. Analyses of foliage presented in an accompanying paper (Reuther, Gardner, Smith, and Roy, 1949) gave average values of about 0.14 per cent $P$ in the leaves of trees from the nonphosphated plots as compared with a little over .15 per cent where $\mathrm{P}_{2} \mathrm{O}_{5}$ at the highest rate was used. The zinc and manganese content of the foliage was increased somewhat by phosphate fertilization, but the copper was decreased.

Van der Plank and Turner (1936) of South Africa found, by applying 40 pounds of either superphosphate or bone meal per tree to Valencias in an area where sour fruit was common, that acidity decreased, total solids slightly increased, and percentage juice increased. Potassium sulfate, at 25 pounds to the tree, increased fruit acidity. The $\mathrm{P}_{2} \mathrm{O}_{5}$ in the juice was increased from .027 per cent to .038 per cent, and $\mathrm{K}_{2} \mathrm{O}$ from .20 to .24 per cent.

In a fertilizer experiment with Washington Navel orange trees on rough lemon stock, in the Northern Transvaal of South Africa, involving various rates and combinations of nitrogen, phosphate, and potassium, Anderssen (1937) found that while yield and size were unaffected by phosphate and potash, rind thickness was less in the trees not fertilized with nitrogen. In these trees (fruit and leaves), phosphorus was high, and the implication drawn by Anderssen is that high phosphorus absorption causes thin rinds. The thickest rinds were on the plots receiving heavy nitrogen and little or no phosphorus. Acidity of the juice was lowest where phosphorus was the highest (that is, in fruit from trees not receiving nitrogen). Greatest waste during storage was in fruit from trees in the non-nitrogen treatments. It is concluded that nitrogen applications to the soil depress phosphorus absorption by the fruit unless large quantities of phosphorus are present in the root zone, and that it is primarily the phosphorus variation in the fruit which affects rind thickness and juice acidity. It was also concluded that high potassium causes a thick rind and high calcium causes an increase in the amount of waste due to mold during storage. In describing the results of four years of fertilizer treatments on Valencia orange trees in South Africa, Morris (1936) noted 
that phosphorus improved juice percentage and soluble solids acid ratio, and caused heavy blossoming. In common .with other investigators, he noted that the largest differences in fruit and tree characteristics were between those receiving variable nitrogen supplies. Allwright (1938), summarizing the results of 3 fertilizer trials started in 1932 on a red sandy loam type of soil in the Western Transvaal on seedlings, navels, and Valencia orange trees, found that, with the navels and Valencias, phosphate increased the yields. In the navels, those treatments which increased yields decreased sizes. Trees receiving sulfate of ammonia produced fruit of coarse external and internal texture, lower juice percentage, and higher acid percentage. The effects of this fertilizer were offset to some extent by superphosphate or bone meal, and superphosphate, in general, produced smooth fruit of higher juice percentage and lower acid. Such fruit was less deeply colored. The phosphate did not increase the foliage or growth of the tree.

Crous (1937) reported the effects of applying 15 pounds of 20 per cent superphosphate in basins around 10-year-old Valencia orange trees in the White River area, South Africa. He found that the percentage acid was reduced, on the average, from 1.75 per cent to 1.59 per cent. The total solids were not significantly affected nor was the percentage juice.

Relative to diagnosing the nitrogen and phosphorus requirements of orange trees, Anderssen and Bathurst (1938) suggest that the nitrogen, phosphorus, and $\mathrm{N} / \mathrm{P}$ ratio in the juice of oranges may show the current needs of the tree for those elements. An N/P ratio of 9 is thought to represent an optimum figure. If lower, $\mathrm{N}$ may be deficient, and if higher, $\mathrm{P}$ may be deficient. It is believed that high nitrogen depresses phosphate absorption. Esselsen and Oberholzer (1939) found, in a series of experiments, that spraying superphosphate solution on the foliage of Valencia trees reduced fruit acidity. A rate of $1 / 2$ pound of 19.1 per cent superphosphate per gallon of water, together with a sticker, such as gum arabic or sheet gelatin, at $11 / 2$ pounds per 100 gallons of water, was recommended for grower trials.

In a series of field experiments in various parts of the Union of South Africa, Bathurst (1945) found that, almost without exception, superphosphate caused a decrease in skin thickness and in the acidity of the juice. In one case, however, there was an increase in yield. "Mottling" of citrus leaves was produced in some cases by superphosphate applications.

In fertilizer trials in Australia, West (1938) found that superphosphate induced mottle leaf in orange trees. This condition was corrected to a considerable degree by zinc sprays. Reuther and Crawford (1946) also found, in a calcareous soil of California, that 20 pounds of superphosphate mixed with the soil of a small plot 4 feet wide, 6 feet long, and 2 feet deep produced zinc deficiency in young grapefruit trees.

Summarizing data from fertilizer experiments with grapefruit in Jamaica, Innes (1946) states that on some soils, yield responses were obtained with superphosphate. Core diameter and skin thickness were increased by potash and decreased by phosphorus. On phosphorus-deficient soils, phosphate decreased acidity, sugar, and vitamin C. Leaf, rind, and fruit analyses reflected the nutritional status of the tree. The critical levels of various nutrients in the leaves were set as follows : nitrogen, 2.3 per cent; phosphorus, less than 
.13 per cent; potassium, about 1.1 per cent. In experiments with Satsuma oranges, Takahashi (1931) found that soil and spray applications of phosphorus reduced fruit acidity.

From this review of the literature it is apparent that, under a wide range of soil and climatic conditions, phosphorus in sufficient amounts tends to decrease rind thickness, acidity, and vitamin $\mathrm{C}$, and to increase juice percentage of citrus fruit. Fruit from phosphate-deficient trees lacks firmness and is often of rather coarse texture both externally and internally, whereas fruit from phosphated plots tends to be smoother. A number of investigators have mentioned that orange color is decreased by phosphorus. The only description of effects of phosphorus lack on foliage and growth reported, other than those of Haas (1936) and Chapman and Brown (1941), is that of Forsee and Neller (1944). The use of leaf, rind, and juice analyses has also been mentioned by a number of investigators as a means of diagnosing phosphorus status, but no complete study of this problem has been reported.

The data reported in this paper not only confirm much of the previous work which has been carried on, but also afford a more complete understanding of growth, appearance, and fruit quality effects than does any work hitherto reported. In addition to this, studies of leaf composition have enabled the authors to establish tentative leaf analysis standards for diagnostic purposes. Also, interesting observations have been made as to disease, fruit breakdown, insect infestation, phosphorus requirements, and secondary effects of phosphate deficiency.

\section{EXPERIMENTAL PROCEDURE}

The 22 trees used in this experiment were Washington Navel oranges budded on sour orange rootstock. One-year-old nursery trees, they were dug and pruned as is done commercially. The roots were thoroughly cleaned of soil by a fairly stiff stream of water from an ordinary hose spray nozzle and transplanted into solution cultures. The containers were 273 -liter vitrified tile with cement bottoms. They were placed out-of-doors in a screened enclosure with the tile buried so that about one fifth protruded aboveground. In June, 1940, the trees were divided into three groups and placed in nutrient solutions of three phosphate levels, as shown in Table 1 . These solutions were continuously aerated, the reaction maintained at $\mathrm{pH} 5.0$, and phosphate, as well as other constituents, kept essentially constant by frequent determination, adjustment, and periodic renewal. The trees grew well, but, as reported in another paper by Chapman and Brown (1942), the roots of the trees growing in solutions of medium and high phosphate levels became infected with Thielavia basicola during the course of the first year and a half of the experiment. However, it was found possible to inhibit this fungus by lowering the $\mathrm{pH}$ of the culture solutions, and from April, 1942, until the termination of the experiment in September, 1949, the solutions were all maintained at approximately $\mathrm{pH} 4.0$. Also, in April, 1942, it was decided to subdivide the 10 trees receiving low phosphate into 3 separate subgroups. The grouping and composition of the culture solutions used from this time on are shown in Table 2 . The phosphate levels maintained from this time forward were $0.10,0.50,0.65,1.50$, and 5.0 milliequivalents per liter. The phosphate levels in each of these groups varied 


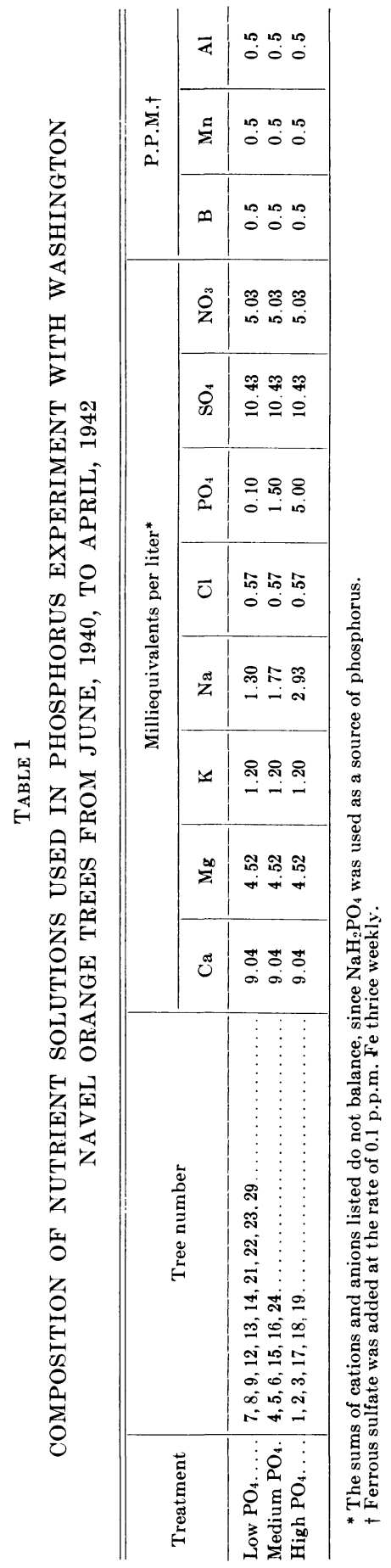

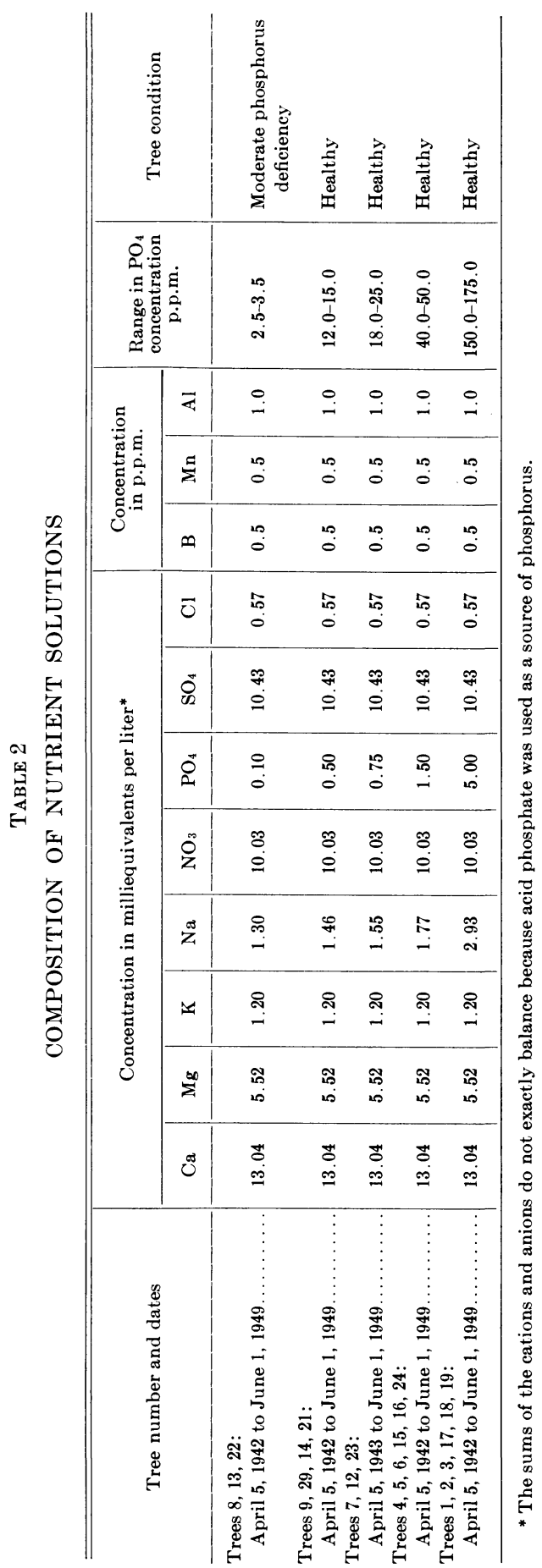


somewhat, of course, but, in general, determination, adjustment, and renewal of the solution were such that the variation within each level was as follows: trees $8,13,22-2.5$ to 3.5 p.p.m. $\mathrm{PO}_{4}$; trees $9,29,14,21-12.0$ to 15.0 p.p.m. $\mathrm{PO}_{4}$; trees 7, 12, 23-18.0 to 25.0 p.p.m. $\mathrm{PO}_{4}$; trees $4,5,6,15,16,2440.0$ to 50.0 p.p.m. $\mathrm{PO}_{4}$; trees $1,2,3,17,18,19-150.0$ to 175.0 p.p.m. $\mathrm{PO}_{4}$. In general, the technique of this experiment was similar to that of a potassium experiment reported previously by Chapman, Brown, and Rayner (1947).

Records of tree performance and systematic notes on both root and top behavior were made at periodic intervals. Both black-and-white and colored photographs were taken of all trees and of such abnormalities as occurred.

The fruit picked from each tree annually was weighed, counted, and graded for rind texture, stem, and stylar-end characteristics. A measure of average size was obtained by cutting each fruit transversely at its point of maximum diameter and measuring diameter in millimeters. At the same time, measurements were made of rind thickness. In some years a representative sample of whole fruit was macerated in a Waring Blender and analyzed for inorganic constituents. The remainder of the fruit was juiced, the juice was strained through a $2-\mathrm{mm}$ sieve, and its percentage was determined from the weight of the whole fruit and the juice. Samples of juice were tested for total solids with a Brix hydrometer, and determinations of acid and vitamin $\mathrm{C}$ were made. The juice was also tasted for palatability and flavor. Diameter measurements were averaged for all of the fruit from a given tree. As a result of oil spraying for scale in the spring of 1943, nearly all of the fruit fell off; hence no fruit data are available for the year 1943-44. No statistical studies were made, and any statements on significance are the authors' interpretation of the data.

\section{RESULTS}

Effect of Phosphorus Deficiency on Growth and Foliage Characteristics. Of the five groups of trees, the only ones to show visible signs of phosphorus lack were those maintained at the lowest phosphate level (trees 8,13 , and 22 maintained at 2.5 to 3.5 p.p.m. $\mathrm{PO}_{4}$ ). The group maintained at the next highest level (trees 9, 29, 14, and 21 at 12.0 to 15.0 p.p.m. $\mathrm{PO}_{4}$ ) bore fruit, some of which showed unmistakable signs of phosphate lack, but at no time was tree appearance other than healthy and green. The trees in the higher phosphate series were healthy and vigorous from 1942 on.

The three trees $(8,13$, and 22) grown in solutions varying from 2.5 to 3.5 p.p.m. $\mathrm{PO}_{4}$ showed signs of phosphorus deficiency from the outset, but during the first years of the experiment the degree of deficiency, as indicated by foliage characteristics, was quite mild. However, from 1946 to the present, the degree of deficiency has become more severe, in spite of the fact that the phosphate concentration in the nutrient medium has been just as rigorously maintained. This suggests that, as the tree grows older, there may be some change in phosphate requirement; either the roots are less effective in absorption or fruit bearing places an extra requirement on the tree. Whatever the explanation, trees 8,13 , and 22 have shown more aggravated symptoms of phosphate lack in the past few years than formerly. The trees were very small when planted and it is improbable that there was enough reserve phosphorus in them to account for the milder deficiency symptoms from 1940 to 1946. 
So far as foliage appearance and growth behavior are concerned, the trees (as with potassium deficiency) showed more acute symptoms in the spring following bloom than at any other time of year. During that period there was an excessive shedding of old leaves. This, of course, gave the tree a thin, defoliated appearance. Twig dieback occurred at that time. Many of the old leaves, but not all, developed burned areas in the margins or tip and then dropped. A twig showing the light-green to bronzed appearance of older leaves, the necrotic blotches referred to, and the evidence of leaf abscission is shown in Plate 1, left. Plate 1, right, shows a more generalized view of foliage as it appears several months after the spring bloom. Note the bronzed, lusterless character of the foliage, the evidence of leaf abscission, and the sparseness of new foliage. Plate 2 shows more of the necrotic burning of leaves caused by phosphorus deficiency.

Plate 3 shows the over-all appearance of a tree that has become acutely deficient in phosphorus. Note thinness of foliage, general light green, lusterless color, and general lack of fruit in contrast to the tree (plate 4) that is in the very earliest stage of phosphorus deficiency and shows no foliage or growth abnormalities whatever. In the latter, the only things to denote phosphorus lack are certain fruit quality characteristics (to be described later). Yield, appearance, and growth in trees under this treatment are comparable in every way to those of trees receiving much higher amounts of phosphorus.

Unlike the leaves of some plants, such as corn and tomatoes, those of phosphorus-deficient trees show no purplish or other especially diagnostic characters. In fact, the general appearance of the tree and foliage is somewhat akin to that of nitrogen deficiency. The chief difference is that a certain amount of new growth continues. The phosphorus for this new growth apparently is translocated from older leaves ; this, in turn, might cause the leaf to absciss prematurely, and the shoots, thus weakened, to die back.

A secondary condition noted on the phosphate-deficient trees was a mild manganese deficiency. This effect was reported in an earlier experiment with orange trees growing in a phosphorus-deficient soil. The explanation offered previously was that decreased respiration of the phosphorus-deficient plant lowered the ability of the plant roots to dissolve manganese. The present solution-culture experiment indicates that some other explanation must be involved. In some manner, lack of phosphorus either keeps the plant root from absorbing manganese or, as seems more likely, utilization or transport of manganese within the plant is interfered with.

Another secondary condition developed to a slight degree in two Valencia orange trees (not included or described in this experiment, but used to obtain supplementary information) which, in June, 1946, were changed from 45 p.p.m. $\mathrm{PO}_{4}$ to 300 p.p.m. This was the appearance of a certain amount of iron chlorosis. These two trees were formerly part of another experiment, but when that terminated, they were used to determine the effects, if any, of amounts of phosphorus twice those of the highest phosphorus levels used in the navel orange experiment. Despite the fact that these two cultures, like all the rest, have been maintained at around $\mathrm{pH} 4.0$ and have received the same amounts of ferrous sulfate as all the other cultures, more or less iron chlorosis has begun to show up. 
Effect of Phosphorus Deficiency on Fruiting Behavior and Fruit Quality. Table 3 shows the effects of the varying phosphate concentrations on the number, weight, and average diameter of the fruit produced during the course of the experiment. As stated, only trees 8,13 , and 22 maintained at phosphate levels of 2.5 to 3.5 p.p.m. showed tangible symptoms of phosphorus deficiency. As the data show, the total number of fruit produced by these trees was much less than for any of the other groups. However, fruit size, as denoted both by the average weight per fruit and by diameter, was greater than that from trees supplied with higher levels of phosphate. In a former experiment with potash, it was clearly demonstrated that lack of potassium resulted in smaller fruit sizes. Lack of phosphorus, however, has an opposite effect. The trees maintained at the next highest phosphate concentrations (12.0 to 15.0 p.p.m. $\mathrm{PO}_{4}$ ) produced just as many fruit as those growing at higher phosphate levels, but, as will be shown later, various quality characteristies were like those of the fruit borne on the phosphate-deficient trees. As regards size, the fruit of trees receiving the two highest phosphate levels was definitely smaller than that grown at the lower phosphate concentrations. Therefore, relative to the very important question of fruit sizes, it is evident that increased potash tends to increase size (Chapman, Brown, and Rayner, 1947) while increased phosphorus tends to reduce it. This increase in size may, of course, be due to the lesser number of fruit produced and the somewhat increased potassium in the phosphorus-deficient tree.

Another observation made from time to time during the course of this experiment was that more of the ripening fruit dropped from the trees lacking phosphorus than from the trees amply supplied. A record of all fruit which dropped between December 1 and the time of fruit harvest was kept, and the data are recorded in Table 4. The data show that, on the average, about one third of all the fruit which remained on the tree up to December 1 fell off between that date and the time of harvest (usually between March 1 and April 15), whereas only from 12 to 18 per cent dropped from the trees receiving higher levels of phosphate.

Effects on Fruit Quality. The data in Tables 5, 6, 7, 8, and 9 are concerned with various quality effects of phosphorus deficiency and the variable levels of phosphate maintained in this experiment.

Effects on Rind Texture, Stem and Navel End Coarseness, and Shape of Fruit. Each year the fruit from all trees was graded as to coarseness of rind and of stem and navel end. (In the navel orange, an elongation and deep creasing of the stem end of the fruit is often seen, and many such fruit are put into lower grades when sorted in the packing house.) In addition, the navel end of the fruit is, in some cases, large, swollen, or protruding. These characteristics result in grade lowering.

At no time was any relation apparent between the navel end of the fruit and phosphate level, hence these data are not recorded in Table 5.

With reference to rind texture, the fruit from phosphorus-deficient trees, in most years, was somewhat coarser than that from the high-phosphorus trees. However, in 1942-43, 1944-45, and 1945-46, there was no significant difference. The fact that, in 4 out of 7 years, rind texture was coarser in the low-phosphorus fruit indicates an effect of phosphorus on this characteristic. 

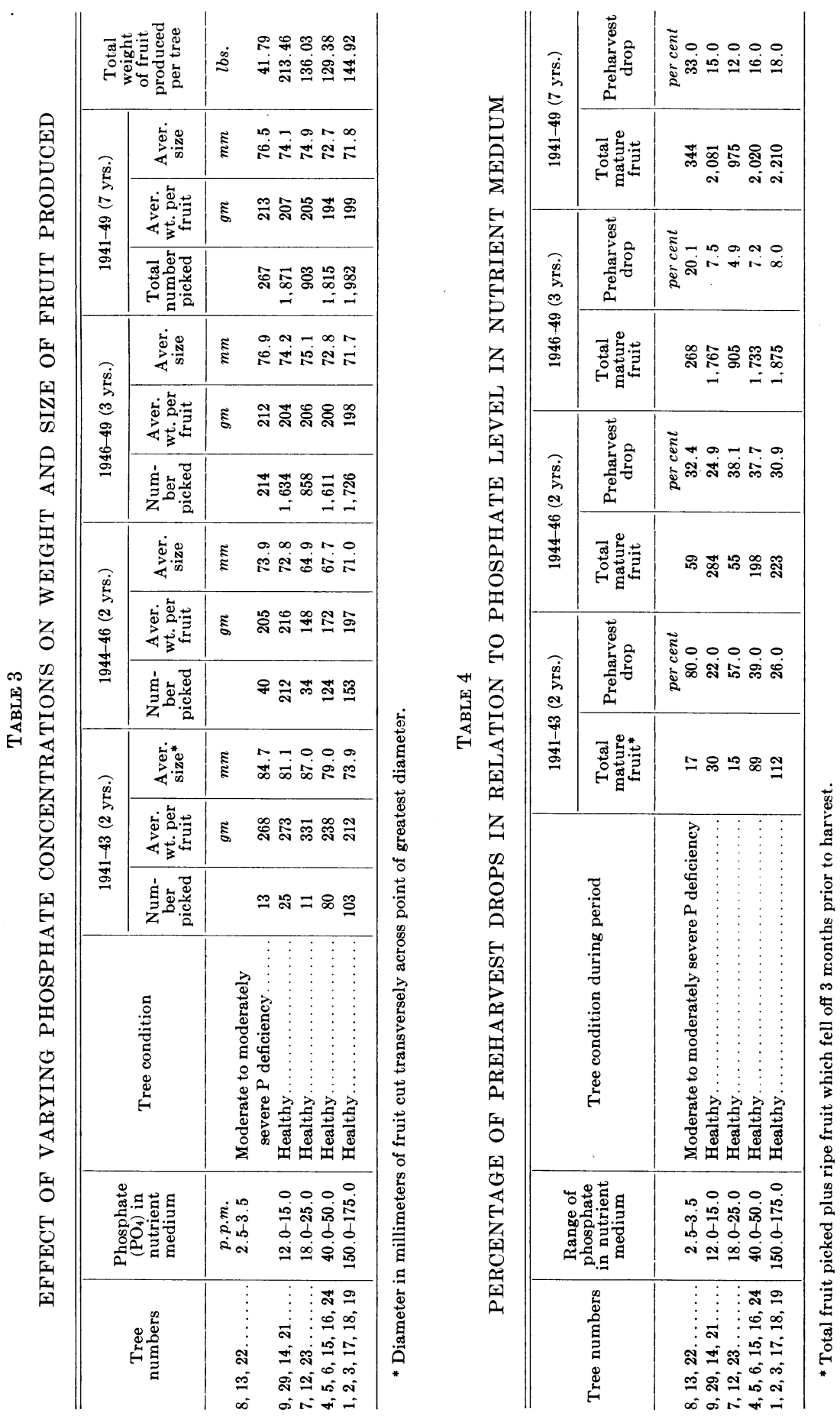
In every year the fruit from the high-phosphorus trees had a high percentage of smoothness.

The same trend was apparent as regards stem-end coarseness. A larger percentage of the fruit from the phosphate-deficient trees had rough, coarse stem ends than did that from the high-phosphorus trees. As noted in effects on size, these results also are just the opposite of those in the potash experiment where increasing levels of potassium somewhat increased fruit coarseness.

Although data are not presented here because of the difficulty of measuring misshapenness, a higher percentage of misshapen, irregular fruit was consistently produced by the phosphorus-deficient trees than by those receiving adequate supplies.

Effect on Puffiness and Hollow Centers. In both navel and Valencia fruit, a condition known as puffiness or creasing occurs commonly. It is more severe in some years than in others, and worse in some sections than in others. The rind separates to some degree from the fruit and peels very easily. In all years the fruit was graded very closely for this character. Another condition that develops as fruit matures is that the central pith shrinks or separates from the segments at the center of the fruit. This condition is commonly referred to as hollow centers. Such fruit is less firm than that in which no separation occurs. Any fruit which showed a detectable amount of puffiness or the slightest separation of the center pith was graded as either being puffy or as having hollow centers. This accounts for the rather low percentage of nonpuffy and solid-center fruit, as shown in Table 6. With regard to puffiness, only in the season of 1946-47 was there more puffy fruit in the phosphorusdeficient group than in the high-phosphorus trees. In all the other years there was just as much puffy fruit in high- as in low-phosphate or phosphatedeficient trees. In 1948-49 there was an especially high percentage of puffy fruit, particularly in certain trees among the high-phosphate cultures. Thus it would appear that if phosphorus is in any way involved in this problem it must be secondary to some more basic or primary factor.

With regard to solid centers and the associated condition of firmness, on the other hand, there was an outstanding phosphorus effect. Trees showing clear-cut phosphorus deficiency symptoms bore fruit much of which showed some separation of the central pith and separation of the segments. This was more pronounced in some years than others. Even in fruit which, at the time of harvest, showed no separation, it was noted that in separating the segments by hand they came apart much more readily than did those in fruit from the high-phosphorus trees. Plate 5 shows the external and internal appearance of fruit from trees with moderately severe phosphorus deficiency. Plate 6 shows both the external and internal appearance of representative fruit from the low-, intermediate-, and high-phosphorus cultures. Note that the lowphosphorus fruits are a little larger, somewhat coarser, have thicker rinds, a little deeper orange color, and separated center pith. Conversely, the highphosphate fruits have thinner rinds, smoother texture, and solid centers. It is especially significant that, though trees $9,29,14$, and 21 , grown at concentrations of 12 to 15 p.p.m. $\mathrm{PO}_{4}$, showed no tangible foliage growth or yield symptoms of phosphate lack, their fruit showed a higher percentage of center pith separation than did the fruit from the higher phosphate series (see 

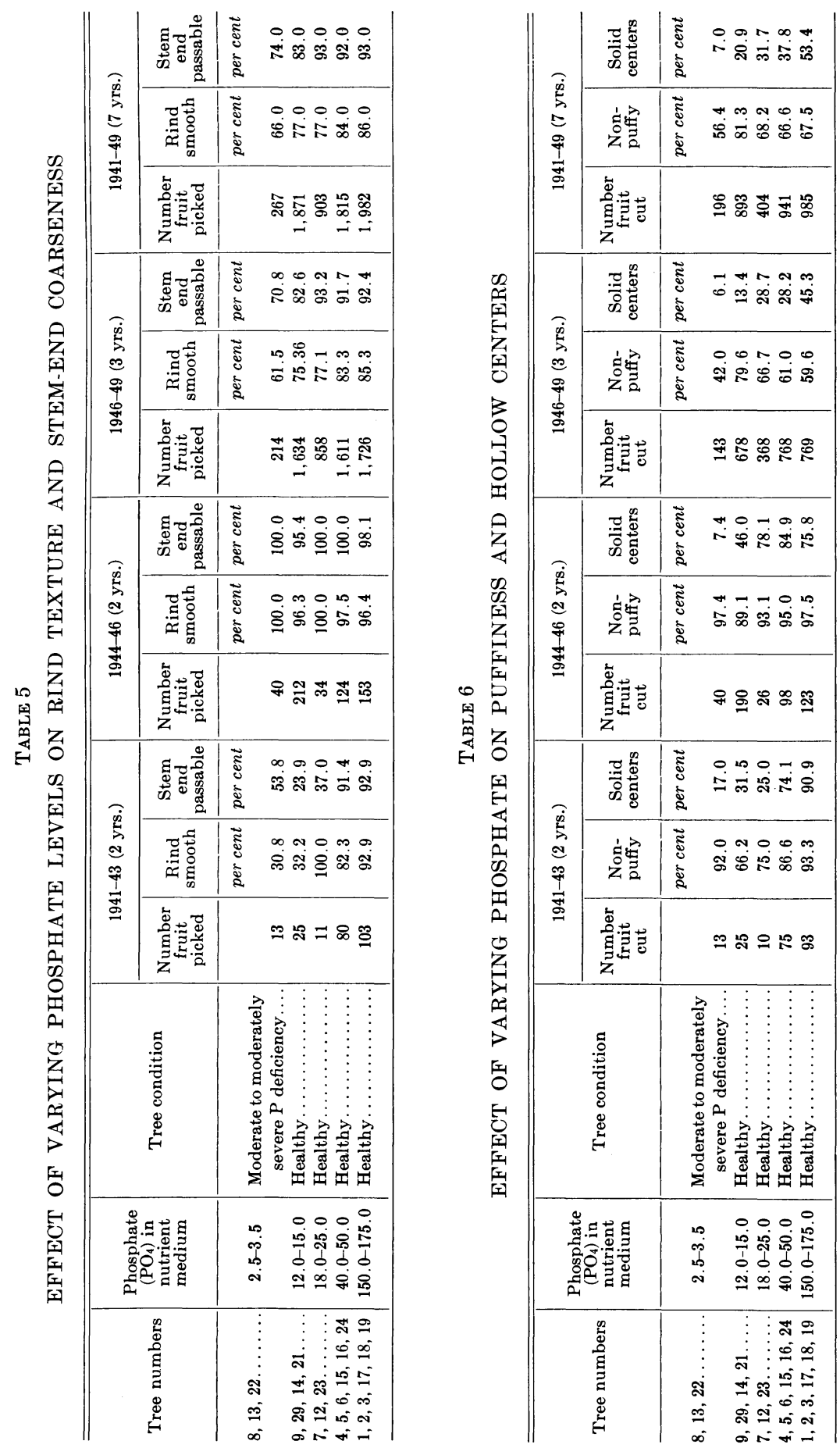
table 6). In general, fruit from these trees was also a little coarser than that from the higher phosphate cultures. This is a highly significant point, for it shows that though a certain phosphate supply is ample for yield and growth, certain fruit characteristies, such as firmness, smoothness, and juice percentage, can be improved by increasing the phosphate supply.

Effect on Juice Percentage. Table 7 shows the percentage juice in fruit from trees grown at varying phosphate concentrations. As might be expected from the preceding statements on coarseness and rind thickness, there was distinctly less juice in the fruit from phosphate-deficient trees than from those getting ample phosphate. This was due not only to thicker rinds, but also to a greater amount of pulp or rag within the fruit.

Effect on Brix; Citric, and Ascorbic Acid. Table 8 shows the Brix and citric acid of the juice from the various cultures. While in most years the low-phosphorus fruit had a definitely higher acid content, the Brix was not much different. There was not any great difference between cultures $9,29,14$, and 21 which showed some of the fruit characteristics associated with pronounced phosphate deficiency, and cultures $1,2,31,17,18$, and 19 , which received the highest phosphate levels. But the 5-year averages showed .84 as against .75 per cent citric acid in the juice from these two sets of cultures. These data are in complete agreement with the field experiments of workers in Florida and other parts of the world. It has been the universal experience that phosphorus fertilization of citrus tends to reduce acidity.

Table 9 shows the data on vitamin C. As with total acidity, increasing phosphate decreases the ascorbic acid content of orange juice. The fruit from phosphorus-deficient trees showed an unusually high average ascorbic acid content- 0.74 as against $0.40 \mathrm{mg} / \mathrm{ml}$ for the high-phosphate fruit.

Effect on Color. Notes were systematically kept on the color of the rind and the juice of each lot of oranges each year. In most years the color of both rind and juice of the phosphate-deficient fruits was a deeper orange than in fruits from the high-phosphate trees. There were one or two years, however, when this was not noticed.

In previous work, reported by Chapman and Brown (1941), with navel orange trees growing in soil cultures lacking phosphorus, fruit was also more deeply colored than that from trees receiving ample phosphate. Forsee and Neller (1944) noted similar effects. Allwright (1938) noted that fruit from trees receiving phosphate were less deeply colored than from trees not receiving phosphate. While it is well known that climatic influences also affect color, our observations and those of others are consistent in showing that phosphate fertilization tends to decrease the orange color of oranges.

Effects on Disease and Insects. As noted earlier, during the first year and a half of the experiment while the trees were grown in solutions maintained at about $\mathrm{pH} 5.0$, the roots of the high-phosphate trees all showed a considerable infestation by the black fungus, Thielavia basicola. The roots of the lowphosphate trees, while all showing some slight infestation, made much better growth and were definitely less seriously invaded by the fungus than were those in the cultures receiving the 45 and 150 p.p.m. $\mathrm{PO}_{4}$ levels. When the $\mathrm{pH}$ of the culture solution was lowered to 4.0 , the fungus infestation gradually disappeared from all cultures. 


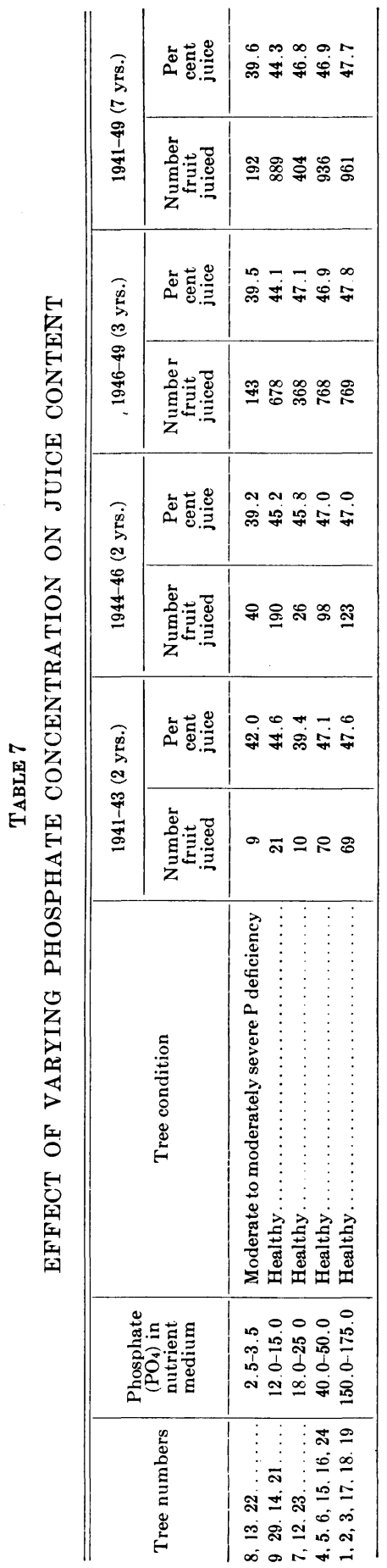

\begin{tabular}{|c|c|c|c|}
\hline & & 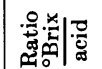 & 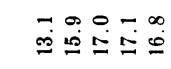 \\
\hline & 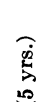 & 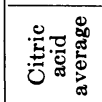 & 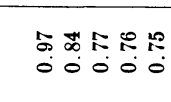 \\
\hline & $\begin{array}{l}\text { P } \\
\text { 苞 }\end{array}$ & 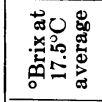 & 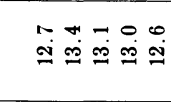 \\
\hline & & 可. & ஜ \\
\hline $\begin{array}{l}0 \\
\theta \\
\text { 是 }\end{array}$ & & 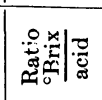 & 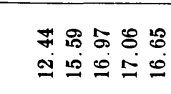 \\
\hline 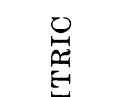 & 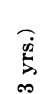 & 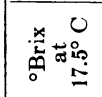 & 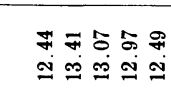 \\
\hline $\begin{array}{l}0 \\
\text { 玄 }\end{array}$ & 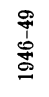 & 蒫 & 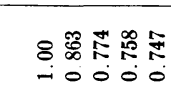 \\
\hline 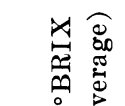 & & 蕞: & 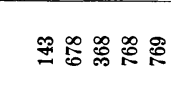 \\
\hline 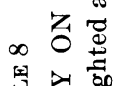 & & 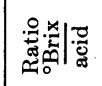 & 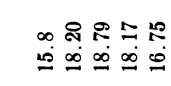 \\
\hline 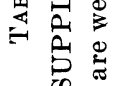 & $\widehat{\widehat{d i d}}$ & 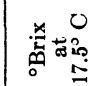 & 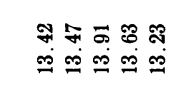 \\
\hline 四 & 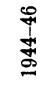 & 递 & 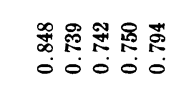 \\
\hline 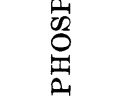 & & 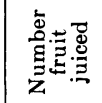 & 요 \& \\
\hline 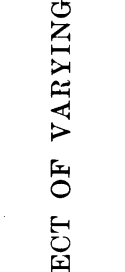 & & 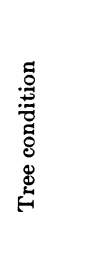 & 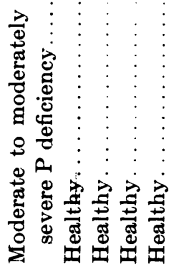 \\
\hline 空 & & 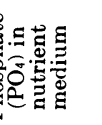 & 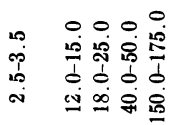 \\
\hline & & 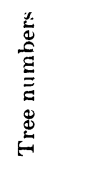 & 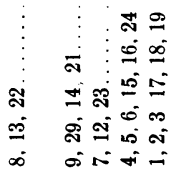 \\
\hline
\end{tabular}




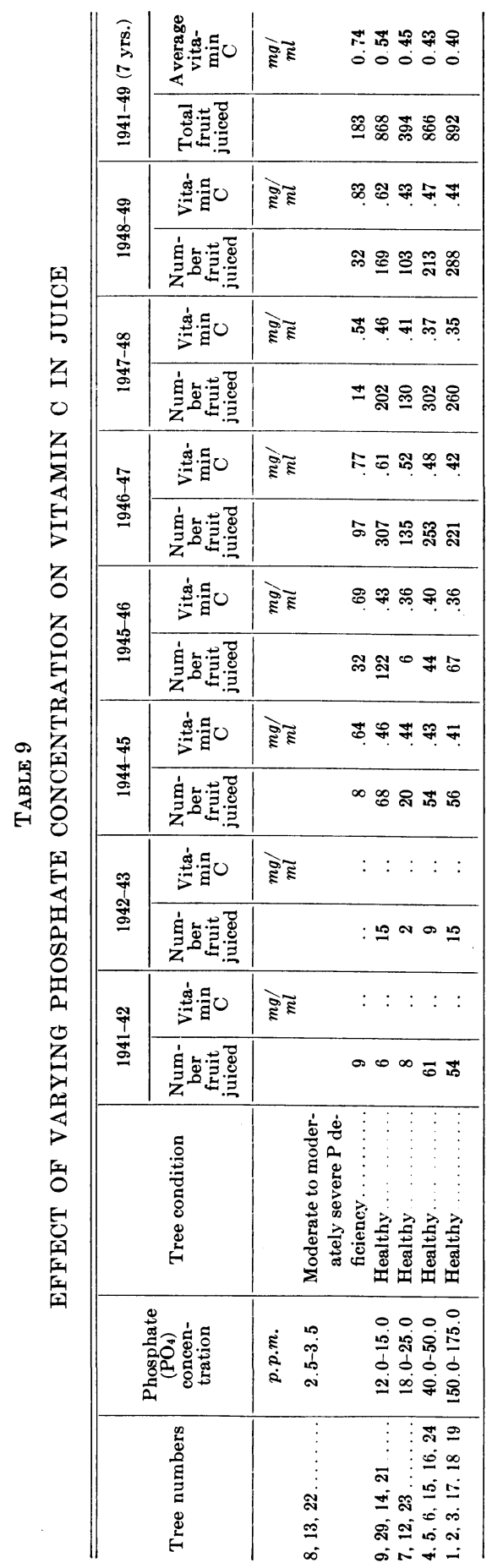


A further observation of importance in connection with the rind breakdown of navel oranges, known as water spot (Klotz, et al., 1948), was that, in 1948 , fruit from the trees lacking phosphate showed a much higher percentage of this trouble than did fruit from the high-phosphate trees. While the fruit and trees of this experiment are in a warm location and did not freeze, a prolonged cold spell, freeze, and, in some areas snow, affected citrus generally in California in January, 1949. Air temperatures at the solution-culture installation reached $28^{\circ} \mathrm{F}$ on several different nights, and snow fell. It is felt that either the low temperatures, the prolonged period of cold, or the snow had something to do with the rind breakdown of the low-phosphorus fruit. This observation is of further interest since some growers, in the area where water spot is a problem, believe that orchards amply fertilized with phosphate are less susceptible to this disorder than are those not fertilized. Moreover, there is evidence from a leaf-analysis survey of groves in the investigation by the senior author that this condition may be somewhat aggravated by high-nitrogen fertilizer. Since low-nitrogen trees are almost invariably higher in phosphate content, it would appear that there is a definite connection between the phosphorus status of the tree and water spot breakdown of orange rinds.

With regard to insect infestation, it was noted in nearly every year of the experiment that red scale infestation of the low-phosphate trees and fruit was markedly less than in the cultures receiving ample phosphate. There also seemed to be less red spider infestation, but this observation was not so definite as that concerning the red scale. No actual measurements of scale populations were made, and it is, therefore, uncertain at what level of phosphate within the plant red scale starts to build up. But it is certain that the phosphate-deficient trees and fruit were only faintly infested at any time, as compared with rather serious infestations on the other trees at certain times.

Effect of Varying Phosphate Levels on the Phosphorus and Other Minerals in Foliage and Fruit. As stated at the outset, one of the objects of this experiment was to determine whether the analysis of some part of the citrus plant for total phosphorus or some phosphorus fraction might provide reliable criteria for evaluating the phosphorus nutrient status of citrus trees. Investigations of this problem are still under way, but during the course of the present experiment many analyses were made of leaves and of fruit from the various groups of trees. These data are of interest not only as bearing on the diagnosis problem, but also in relation to the effects of phosphorus deficiency and increasing levels of that element on the amounts of other inorganic constituents in the leaves and fruit.

Table 9 shows the effects of varying maintained phosphate levels on the calcium, magnesium, potassium, nitrogen, and phosphorus content of orange leaves. These analyses were made on spring-cycle leaves picked at three different dates during the summer of 1944 . At that time, trees 8,13 , and 22 were showing moderate phosphorus deficiency. The other groups of trees were all healthy. As was expected from earlier work, the leaves of the phosphatedeficient trees were substantially higher in total nitrogen than were leaves from the other cultures. However, there was no difference whatsoever between the trees grown at the 12 to 15 p.p.m. $\mathrm{PO}_{4}$ level, and those grown at the 150 
to 175 p.p.m. level. There has been some field evidence on fruit trees (Lilleland, 1932) that excessive phosphate may produce nitrogen deficiency, and the authors noted that evidences of nitrogen deficiency appeared in a heavily phosphate-fertilized soil in oil drums cropped to navel orange trees. It would look as though the nitrogen-starvation symptoms brought on by heavy phosphate fertilization may not be due to depressed nitrogen absorption as such, but rather to some indirect effect. Perhaps high phosphate, in some manner, causes or encourages a breakdown and gaseous release of nitrogen from the soil.

It will be noted from Table 10 that the phosphorus-deficient leaves were definitely higher in potassium and lower in calcium. They were low in total phosphorus, as might be expected. The effects of phosphorus deficiency on composition of leaves grown under the conditions of this experiment are consistent with those reported previously by Chapman and Brown (1941) where the trees were grown in phosphate-deficient soil. Mention should again be made of the fact that the phosphorus-deficient trees showed definite and unmistakable manganese deficiency patterns.

The effects of phosphorus deficiency and increasing levels of phosphorus on the inorganic composition of the rind, pulp, and juice of mature navel oranges is shown in Table 11. In contrast to the effect on leaf composition, the rind, pulp, and juice of fruit from phosphorus-deficient trees were lower in nitrogen than were these same fractions of fruit from the high-phosphorus cultures. No clear-cut difference or trend is apparent in the percentages of other constituents in the rind, pulp, and juice from the various cultures save that phosphorus was lower in fruit from the low-phosphorus cultures, and calcium was somewhat lower in the rind of the phosphorus-deficient fruit.

Relative to leaf analysis as a measure of phosphorus status, consecutive analyses of leaves were made every month from May of one year until April of the following year. The leaves in any one month were taken, for the most part, from spring-cycle twigs of each tree in each treatment; some of the leaves were from fruit-bearing, other from nonfruit-bearing twigs. Thus the May leaves were quite young and tender and about one month old; the July leaves were mature and three months old, etc. The results for the same month in consecutive years were averaged, as were the individual tree results in the group of similarly treated trees. In this way, certain year-to-year and individual tree fluctuations were averaged out. The results of the study are presented in Table 12 and show the average total phosphorus content of leaves from trees grown in solutions of variable phosphate content.

It will be noted that no matter in what month the leaves were picked, there was a definite and consistent correlation between the phosphorus content of the leaves and that of the nutrient medium. The leaves of the high-phosphorus cultures contained roughly twice as much total phosphorus as those of the phosphorus-deficient cultures, although the spread in concentration of phosphate in the nutrient medium, between the highest and lowest, was nearly fifty-fold. These data show definitely that, by increasing the phosphate content of a nutrient medium sufficiently, it is possible to boost the phosphorus content of the leaves, and that there is a rough proportion between phosphate supply in the nutrient medium and that in the leaves. However, the fact that 
TABLE 10

EFFECT OF VARYING PHOSPHATE CONCENTRATIONS ON INORGANIC COMPOSITION OF ORANGE LEAVES

\begin{tabular}{|c|c|c|c|c|c|c|c|c|}
\hline \multirow{2}{*}{ Tree nos. } & \multirow{2}{*}{$\begin{array}{c}\text { Phosphate } \\
\text { (PO4) } \\
\text { in nutrient } \\
\text { medium }\end{array}$} & \multirow{2}{*}{ Tree condition } & \multirow{2}{*}{$\begin{array}{c}\text { Date leaves } \\
\text { picked* }\end{array}$} & \multicolumn{5}{|c|}{$\begin{array}{l}\text { Inorganic composition- } \\
\text { per cent dry matter }\end{array}$} \\
\hline & & & & $\mathrm{Ca}$ & $\mathrm{Mg}$ & $\mathrm{K}$ & $\mathrm{N}$ & $\mathbf{P}$ \\
\hline $8,13,22$ & $2.5-3.5$ & Moderate P deficiency & $\begin{array}{r}6 / 15 / 44 \ldots \ldots \\
7 / 13 / 44 \ldots \ldots \\
8 / 15 / 44 \ldots \ldots \\
\\
\text { Average. . . }\end{array}$ & $\begin{array}{l}3.90 \\
3.81 \\
3.75 \\
3.82\end{array}$ & $\begin{array}{l}0.32 \\
0.28 \\
0.25 \\
0.28\end{array}$ & $\begin{array}{l}1.39 \\
1.14 \\
1.38 \\
1.30\end{array}$ & $\begin{array}{l}3.03 \\
3.80 \\
3.58 \\
3.47\end{array}$ & $\begin{array}{l}0.099 \\
0.079 \\
0.069 \\
0.082\end{array}$ \\
\hline $9,29,14,21$ & $12.0-15.0$ & Healthy & $\begin{array}{r}6 / 15 / 44 \ldots \ldots \\
7 / 13 / 44 \ldots \ldots \\
8 / 15 / 44 \ldots \ldots \\
\\
\text { Average.... }\end{array}$ & $\begin{array}{l}4.58 \\
4.81 \\
4.76 \\
4.72\end{array}$ & $\begin{array}{c}0.36 \\
0.29 \\
0.29 \\
0.31\end{array}$ & $\begin{array}{l}1.35 \\
1.04 \\
1.11 \\
1.17\end{array}$ & $\begin{array}{l}2.53 \\
2.92 \\
2.86 \\
2.77\end{array}$ & $\begin{array}{l}0.182 \\
0.128 \\
0.131 \\
0.147\end{array}$ \\
\hline $7,12,23$ & $18.0-25.0$ & Healthy & $\begin{array}{r}6 / 15 / 44 \ldots \ldots \\
7 / 13 / 44 \ldots \ldots \\
8 / 15 / 44 \ldots \ldots \\
\\
\text { Average.... }\end{array}$ & $\begin{array}{l}4.46 \\
4.52 \\
4.52 \\
4.50\end{array}$ & $\begin{array}{l}0.31 \\
0.30 \\
0.28 \\
0.30\end{array}$ & $\begin{array}{l}1.25 \\
1.03 \\
1.04 \\
1.11\end{array}$ & $\begin{array}{c}2.44 \\
2.94 \\
2.95 \\
2.78\end{array}$ & $\begin{array}{l}0.188 \\
0.140 \\
0.133 \\
0.153\end{array}$ \\
\hline $4,5,6$ & $40.0-50.0$ & Healthy & $\begin{array}{r}6 / 15 / 44 \ldots \ldots \\
7 / 13 / 44 \ldots \ldots \\
8 / 15 / 44 \ldots \ldots \\
\\
\quad \text { Average.... }\end{array}$ & $\begin{array}{l}4.51 \\
4.53 \\
4.71 \\
4.58\end{array}$ & $\begin{array}{r}0.31 \\
0.29 \\
0.29 \\
0.30\end{array}$ & $\begin{array}{l}1.23 \\
1.14 \\
1.11 \\
1.16\end{array}$ & $\begin{array}{l}2.66 \\
2.80 \\
2.77 \\
2.74\end{array}$ & $\begin{array}{l}0.160 \\
0.129 \\
0.126 \\
0.138\end{array}$ \\
\hline $15,16,24$ & $40.0-50.0$ & Healthy & $\begin{array}{r}6 / 15 / 44 \ldots \ldots \\
7 / 13 / 44 \ldots \ldots \\
8 / 15 / 44 \ldots \ldots \\
\\
\text { Average.... }\end{array}$ & $\begin{array}{l}4.26 \\
4.92 \\
4.81 \\
4.66\end{array}$ & $\begin{array}{l}0.32 \\
0.28 \\
0.32 \\
0.31\end{array}$ & $\begin{array}{l}1.32 \\
1.11 \\
1.12 \\
1.18\end{array}$ & $\begin{array}{r}2.45 \\
2.89 \\
2.96 \\
2.77\end{array}$ & $\begin{array}{l}0.175 \\
0.134 \\
0.131 \\
0.147\end{array}$ \\
\hline $1,2,3$ & $150.0-175.0$ & Healthy & $\begin{array}{r}6 / 15 / 44 \ldots \ldots \\
7 / 13 / 44 \ldots \ldots \\
8 / 15 / 44 \ldots \ldots \\
\\
\text { Average.... }\end{array}$ & $\begin{array}{r}5.00 \\
4.59 \\
4.87 \\
4.82\end{array}$ & $\begin{array}{l}0.35 \\
0.29 \\
0.26 \\
0.30\end{array}$ & $\begin{array}{l}1.34 \\
1.03 \\
1.17 \\
1.18\end{array}$ & $\begin{array}{l}2.60 \\
2.75 \\
2.82 \\
2.72\end{array}$ & $\begin{array}{l}0.180 \\
0.171 \\
0.152 \\
0.168\end{array}$ \\
\hline $17,18,19$ & $150.0-175.0$ & Healthy & $\begin{array}{r}6 / 15 / 44 \ldots \ldots \\
7 / 13 / 44 \ldots \ldots \\
8 / 15 / 44 \ldots \ldots \\
\\
\text { Average.... }\end{array}$ & $\begin{array}{l}4.45 \\
4.52 \\
4.55 \\
4.51\end{array}$ & $\begin{array}{l}0.28 \\
0.26 \\
0.29 \\
0.28\end{array}$ & $\begin{array}{l}1.43 \\
1.08 \\
1.00 \\
1.17\end{array}$ & $\begin{array}{l}2.51 \\
2.99 \\
2.81 \\
2.77\end{array}$ & $\begin{array}{l}0.190 \\
0.165 \\
0.153 \\
0.169\end{array}$ \\
\hline
\end{tabular}

* 1944 spring-cycle leaves.

it requires a marked increase in the phosphate level of the substrata to raise the phosphate of the leaves probably accounts for the failure, in many field trials, to increase the phosphorus in citrus leaves by soil application even though it can be shown that phosphorus has penetrated into the root zone. Anderssen (1937) and Finch and McGeorge (1945) have suggested that high nitrogen supply tends to prevent phosphate absorption by citrus. The authors have never been able to verify this in their controlled nutritional experiments and believe rather that it is merely a question of phosphate supply coupled 


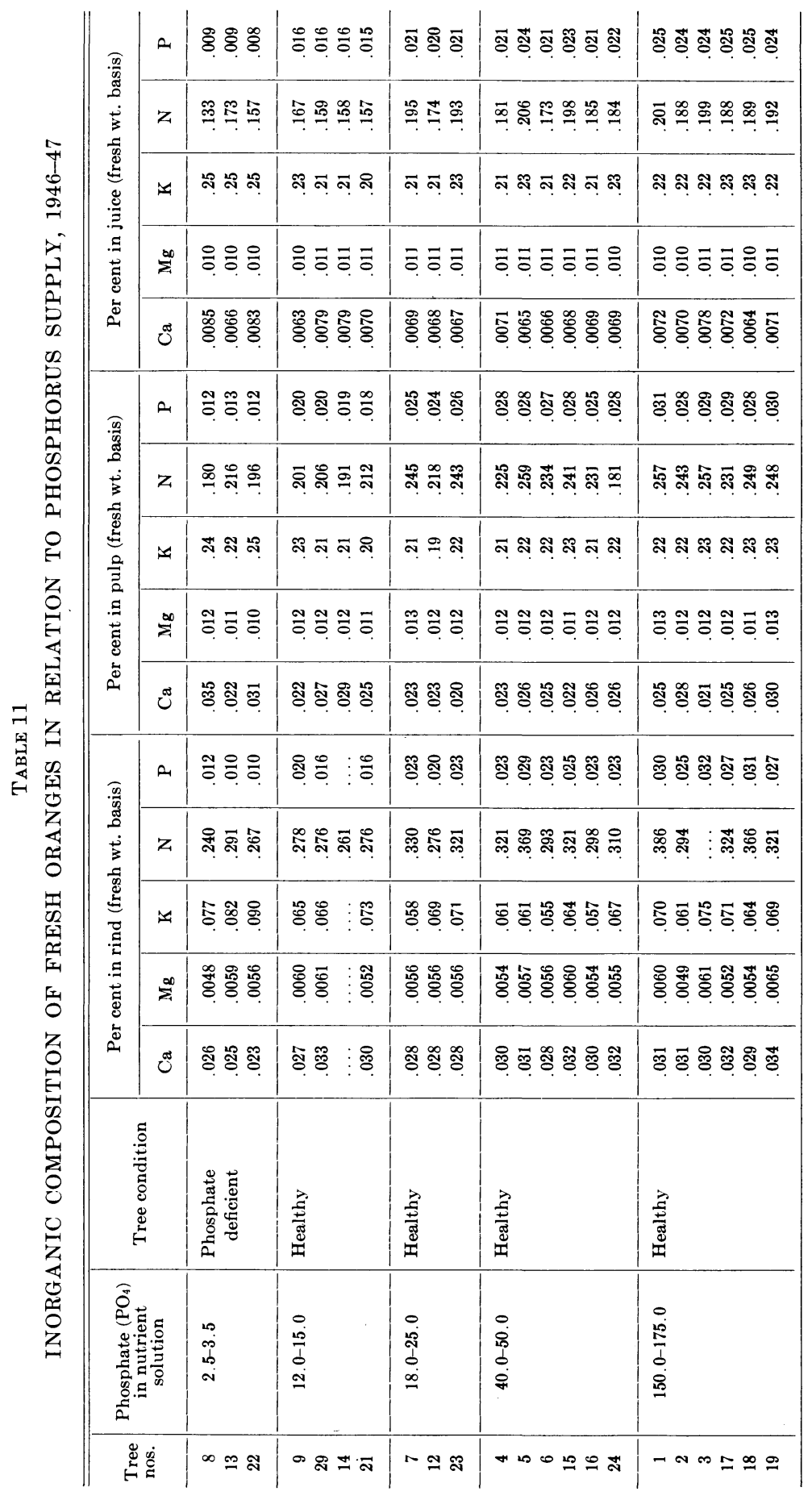


perhaps, as suggested by Williams (1948) and Wallihan (1951), with some controlling internal mechanisms within the plant. There may, of course, be circumstances when high levels of calcium accompany the nitrate ion in which, due to the calcium, phosphate solubility is decreased.

With reference to seasonal changes of phosphorus in leaves, these data show that phosphorus in spring-cycle leaves increases gradually throughout the growing season, reaching a peak in the period September to January. There is some falling off in February, March, and April. This coincides with

TABLE 12

TOTAL PHOSPHORUS IN SPRING-CYCLE LEAVES COLLECTED AT VARIOUS INTERVALS FROM TREES GROWN IN SOLUTIONS OF VARIABLE PHOSPHATE CONCENTRATIONS

\begin{tabular}{|c|c|c|c|c|c|c|c|}
\hline \multirow[b]{2}{*}{$\begin{array}{c}\text { Years } \\
\text { averaged }\end{array}$} & \multirow[b]{2}{*}{ Month } & \multirow[b]{2}{*}{$\begin{array}{l}\text { Age of } \\
\text { leaves } \\
\text { (mos.) }\end{array}$} & \multicolumn{5}{|c|}{ Per cent total phosphorus in dry matter of leaves } \\
\hline & & & $\begin{array}{l}\text { Phosphorus- } \\
\text { deficient trees } \\
\text { nos. 8, 13, 22 } \\
\text { at 2.5-3.5 } \\
\text { p.p.m. } \mathrm{PO}_{4}\end{array}$ & $\begin{array}{c}\text { Low- } \\
\text { phosphorus } \\
\text { trees nos. } 9 \text {, } \\
29,14,21 \text { at } \\
12 \text { to } 15 \\
\text { p.p.m } \mathrm{PO}_{4}\end{array}$ & $\begin{array}{c}\text { High- } \\
\text { phosphorus } \\
\text { trees nos. } 7 \\
12,23 \text { at } 18 \text { to } \\
25 \text { p.p.m. } \text { PO }_{4}\end{array}$ & $\begin{array}{c}\text { High- } \\
\text { phosphorus } \\
\text { trees nos. } 4, \\
5,6,15,16,24 \\
\text { at } 40 \text { to } 50 \\
\text { p.p.m } \mathrm{PO}_{4}\end{array}$ & $\begin{array}{c}\text { High- } \\
\text { phosphorus } \\
\text { trees nos. } 1, \\
2,3,17,18,19 \\
\text { at } 150 \text { to } 175 \\
\text { p.p.m. } \mathrm{PO}_{4}\end{array}$ \\
\hline $1947-48(2)$ & May & 1 & 0.061 & 0.080 & 0.103 & 0.114 & 0.132 \\
\hline $1946-48(3)$ & June & 2 & 0.072 & 0.105 & 0.127 & 0.131 & 0.148 \\
\hline $1946-48(3)$ & July & 3 & 0.073 & 0.095 & 0.131 & 0.145 & 0.155 \\
\hline $1946-48(3)$ & Aug. & 4 & 0.077 & 0.107 & 0.127 & 0.135 & 0.149 \\
\hline $1946-48(3)$ & Sept. & 5 & 0.082 & 0.117 & 0.138 & 0.141 & 0.161 \\
\hline $1946-48(3)$ & Oct. & 6 & 0.087 & 0.113 & 0.135 & 0.137 & 0.155 \\
\hline $1946-48(3)$ & Nov. & 7 & 0.094 & 0.119 & 0.139 & 0.144 & 0.158 \\
\hline $1947-49(3)$ & Dec. & 8 & 0.090 & 0.114 & 0.137 & 0.141 & 0.159 \\
\hline $1947-49(3)$ & Jan. & 9 & 0.090 & 0.115 & 0.137 & 0.147 & 0.169 \\
\hline $1947-49(3)$ & Feb. & 10 & 0.082 & 0.105 & 0.122 & 0.137 & 0.158 \\
\hline $1947-49(3)$ & Mar. & 11 & 0.067 & 0.089 & 0.114 & 0.121 & 0.137 \\
\hline $1947-49(3)$ & Apr. & 12 & 0.058 & 0.074 & 0.098 & 0.106 & 0.127 \\
\hline Average & $\begin{array}{l}\text { May } \\
\text { through } \\
\text { April }\end{array}$ & & .08 & .10 & .13 & .13 & .15 \\
\hline
\end{tabular}

the period of new spring growth and suggests that, at this time, phosphorus is translocated from old leaves to emerging new growth. Data not presented here also suggest that there is movement of phosphorus from leaves to developing fruit.

Because the figures presented in Table 12 are averages of 2 to 3 years, yearly variations in the phosphorus level of similarly aged leaves from trees grown under conditions of uniform culture do not show up. However, it has been found that such variations occur and this makes interpretation of phosphate status on the basis of single samples of leaves a little uncertain.

From the standpoint of diagnostic method and standards, these, and a great many other data suggest that, until some better criteria are available, spring-cycle leaves that are picked during the period of September through December (5- to 8-month-old leaves) and that show total phosphorus in the dry matter of 0.11 per cent or less should be suspected of indicating phosphorus deficiency. On the other hand, amounts of 0.12 per cent $\mathrm{P}$ and greater 
probably represent an ample supply. While these values are to be regarded as tentative, they will serve as a guide until more precise methods and more correlative field information are available.

Phosphorus Levels in Nutrient Solutions Requisite for Optimum Citrus Growth and Performance. While data obtained under solution- or sand-culture conditions cannot be translated directly in terms of soil, it is nonetheless useful to know the limiting concentrations of various elements or solutions below which plants cannot obtain enough to meet their requirements. In the case of phosphorus, a rather curious situation prevails. Parker (1927) found that if concentrations were maintained, plants such as corn could secure adequate phosphorus from solutions containing less than 0.5 p.p.m. $\mathrm{PO}_{4}$. Under the conditions of this experiment, however, the citrus trees grown in aerated cultures maintained at 2.5 to 3.5 p.p.m. $\mathrm{PO}_{4}$ developed definite phosphorus-deficiency symptoms. By frequent analysis and adjustment, it is known that during the nine years of this experiment concentrations rarely, if ever, fell below 2.5 p.p.m. $\mathrm{PO}_{4}$. Yet, under field conditions, citrus can secure adequate phosphate from soil in which corn, tomatoes, and so forth grow very poorly without supplemented phosphate. In other words, though citrus cannot get enough phosphorus from solutions that contain adequate quantities for corn, under soil conditions it can get along where corn fails. This suggests that, in the soil, intimate root-soil particle feeding, or, as Jenny might term it, "contact effects," plays a greater role with citrus than with rapidly growing plants such as corn. This in turn suggests that water extraction methods, such as that described by Bingham (1949), are likely to be more successful in predicting phosphate needs of field and garden crops than of citrus trees. The rate of root growth in citrus is much slower than that of quick-growing crops and it is therefore essential that nutrient absorption take place through older, somewhat suberized feeder roots. It is probable that substantial parts of the phosphorus, potassium, iron, zinc, manganese, and other nutrients not readily soluble in the soil solution are available to citrus through intimate root-soil particle contact effects. These effects are probably of greater importance in citrus than in quickgrowing plants.

\section{DISCUSSION AND CONCLUSIONS}

The results of this experiment serve both to confirm and tie together the scattered data concerning the effects of phosphorus on citrus, and enable us to present a rather comprehensive picture of the effects of phosphorus deficiency on citrus.

With reference first to tree appearance, the very earliest stages of phosphorus deficiency produce no effect on foliage, growth, blossom, or yield. In this respect, the situation is similar to potassium deficiency. Fruit quality is, however, affected to some degree. The principal effects on fruit are a tendency to lack of firmness, a little greater average rind thickness, a trifle coarser external and internal texture, slightly lower juice percentage, a trifle larger size, and slightly higher acid. When phosphorus deficiency reaches the stage where moderate foliage and yield effects are discernible, the above fruit quality effects are more conspicuous. On the other hand, increasing phos- 
phorus makes for more even sizes, a slight reduction in average size, smoother texture, thinner rinds, less deeply colored rind and juice, lower acid, lower vitamin $\mathrm{C}$, and higher juice percentage. An outstanding characteristic is the firmness of such fruit.

A further interesting effect, not previously mentioned by anyone so far as the authors are aware, was the greater percentage of the rind breakdown disorder known as water spot in the low-phosphorus fruit produced in 1949. As stated, a prolonged cold spell occurred in January, 1949, and since the effect was not seen in other years, it seems certain that there is some interaction between climate, phosphorus level, and water spot. Another observation was that red scale was much more prevalent on the trees and fruit of the cultures amply supplied with phosphorus, and a root-infecting fungus, Thielavia basicola, was worse on trees of the high-phosphorus cultures than on the low-phosphorus ones. Symptoms of iron chlorosis were noted on some very high phosphate cultures, whereas manganese deficiency leaf patterns developed on the phosphorus-deficient trees.

These data all suggest that the best possible results, from the standpoint of fruit size, quality, tree condition, scale infestation, and perhaps susceptibility to root organisms, would be achieved by a phosphate level maintained just slightly above that in which the first symptoms of a phosphorus lack on fruit become manifest. Indiscriminate use of phosphorus and its resulting accumulation in citrus groves are not desirable. There is evidence to show that zine, manganese, and iron deficiencies are aggravated, that nitrogen fertilizer is less effective, and that unfavorable pathogenic fungi may be encouraged. On the basis of the tentative leaf-analysis standards growing out of this experiment, it is suggested that the ideal phosphate status would be represented by values in 5- to 8-month-old, spring-cycle leaves of 0.12 to 0.13 per cent total phosphorus. It is hoped that future work will lead to the development of more and better criteria, but there is good evidence that a closer regulation of phosphate supply, to prevent both deficiencies and excesses, is highly desirable.

All of the work thus far reported shows that moderate to severe phosphorus deficiency is characterized by a bronzing of the foliage, premature abscission of leaves, an especially heavy leaf fall following spring bloom, some dieback of weakened twigs, and necrotic burning of old leaves, either of the tips or sides (see plates 1 and 2 ). No leaf pattern is associated with this disorder save that in this and a former experiment, as noted, manganese-deficient patterns showed up as a secondary condition caused by phosphorus deficiency.

With reference to the effect of phosphorus on other constituents, leaves from phosphorus-deficient trees were high in nitrogen and potassium, but low in calcium. There was no indication, however, that high phosphate depressed nitrogen absorption. Under the conditions of this experiment it required a fifty-fold increase in phosphate content of the culture solution to double the total phosphorus in the leaves. This may account for the fact that, under field conditions, ordinary or even fairly heavy applications of phosphate to the soil do not increase the total phosphorus of leaves.

In contrast to earlier work by other investigators, where it was shown that a maintained level of 0.2 to 0.5 p.p.m. $\mathrm{PO}_{4}$ was ample for optimum growth 
of corn and other crops, the present experiment shows that a maintained level of 2.5 to 3.5 p.p.m. $\mathrm{PO}_{4}$ was insufficient for citrus, and the trees of those cultures developed pronounced phosphorus-deficiency symptoms. This behavior, under solution culture conditions, is in marked contrast to behavior in the soil, for there a citrus tree can secure adequate phosphate under conditions where field and garden crops fail. This suggests that with citrus, and perhaps other trees where root growth is cyclic and slow, as contrasted with field and garden crops, a larger proportion of needed phosphate is obtained by contact feeding than is the ease with the quick-growing crops.

\section{SUMMARY}

Washington Navel orange trees on sour orange rootstock were grown outof-doors in large-sized, aerated solution cultures maintained at phosphorus levels ranging from 2.5-3.5 to 150-175 p.p.m. $\mathrm{PO}_{4}$ for a period of nine years. These levels of phosphate made it possible to determine the effects of two degrees of phosphate deficiency and of phosphate levels in excess of plant needs, on tree growth, appearance, behavior, yield, quality of fruit, disease and insect infestation, and foliage composition.

The main findings are briefly covered in the preceding section.

\section{ACKNOWLEDGMENTS}

Miscellaneous help was rendered from time to time in the course of the experiment by George F. Liebig, Jr., and analyses of orange leaves and fruit were made at various times by S. M. Brown (deceased), D. G. Aldrich, and E. F. Wallihan. For all this assistance the authors are grateful. 


\section{LITERATURE CITED}

Allwright, W. J.

1938. Final report on the fertilizer trials at Rustenberg, Western Transvaal. Citrus Grower 52:5-19.

ANDERssen, F. G.

1937. Citrus manuring-its eff ect on cropping and on the composition and keeping quality of oranges. Jour. Pomol. and Hort. Sci. 15:117-159.

Anderssen, F. G., and A. C. Bathurst.

1938. Nitrogen and phosphorus in oranges. Farming in So. Africa 13:349-352.

Bathurst, A. C.

1945. The effects of superphosphate on orange trees. Farming in So. Africa 20:351-353.

Bingham, Frank T.

1949. Soil test for phosphate. California Agr. 3:11, 14.

Chapman, H. D., and S. M. Brown.

1941. The effects of phosphorus deficiency on citrus. Hilgardia 14:161-181.

1942. Some fungal infections of citrus in relation to nutrition. Soil Sci. 54:303-312.

Chapman, H. D., S. M. Brown, and George F. Liebig, JR.

1943. Some effects on citrus fruit quality of nitrogen, phosphorus and potassium. California Citrogr. 28 (8 and 9):198, 211, 230-246.

Chapman, H. D., S. M. Brown, and D. S. Rayner.

1947. Effects of potash deficiency and excess on orange trees. Hilgardia 17:619-650.

Collison, S. E.

1913. Influence of soil and fertilizer on citrus fruits. Fla. State Hort. Soc. Proc. $26: 168-172$.

Crous, P. A.

1937. Superphosphate experiment, White River 1937. Citrus Grower 51:15-17.

ESSELsen, D. J., and P. C. J. OBERHolzer.

1939. Reduction of acid in valencias; effect of superphosphate sprays. Farming in So. Africa 14:(114):21-22.

Finch, A. H., and W. T. McGeorge.

1939. Studies of grapefruit fertilization in Arizona. Amer. Soc. Hort. Sei. Proc. 37:62-67.

1945. Fruiting and physiological responses of Marsh grapefruit trees to fertilization. Arizona Agr. Exp. Sta. Tech. Bul. 105.

Forsee, W. T., JR., and J. R. NFLLER.

1944. Phosphate response in a Valencia grove in the Eastern Everglades. Fla. State Hort. Soc. Proc. 57:110-115.

HAAS, A. R. C.

1936. Phosphorus deficiency in citrus. Soil Sci. 42:93-117.

HILGEMAN, R. H.

1941. Studies of the ripening of Marsh grapefruit in Arizona with special reference to the improvement of maturity measurements. Arizona Agr. Exp. Sta. Tech. Bul. 89.

INNES, R. F.

1946. Fertilizer experiments on grapefruit in Jamaica. Trop. Agr., Trinidad, 23:131-134.

Jones, Winston W., and E. R. PARKer.

1949. Effects of nitrogen, phosphorus and potassium fertilizer and of organic materials on the composition of Washington navel orange juice. Amer. Soc. Hort. Sci. Proc. 53:91-102.

Klotz, Leo J., A. M. Boyce, H. D. Chapman, G. E. Carman, Cluarence Cree, W. W. Jones, L. A. Riehl, W. B. Sinclatr, E. R. Parker, W. S. Stewart, and F. M. Turrell.

1948. Water spot of navel oranges: studies of the problem to 1948. Lithoprint, Univ. Calif. Agr. Exp. Sta. 


\section{LILLELAND, OMUND.}

1932. Experiments in $\mathrm{K}$ and $\mathrm{P}$ deficiencies with fruit trees in the field. Amer. Soc. Hort. Sci. Proc. 29:272-276.

MORRIS, A. A.

1937. The effect of differential fertilizer treatments on the yield and quality of fruit from mature bearing Valencia late trees on Mazoe Citrus Estate, Southern Rhodesia. Brit. So. Africa Co. Pub. 6. Mazoe Citrus Exp. Sta. Rept. 1936:107-153.

PARKer, E. R., and L. D. Batchelor.

1942. Effects of fertilizers on orange yields. California Agr. Exp. Sta. Bul. 673:1-39.

PARKER, F. W.

1927. Soil phosphorus studies. III. Plant growth and the absorption of phosphorus from culture solutions of different phosphate concentrations. Soil Sei. 24:129-145.

Reuther, Walter, Frank E. Gardner, Paul F. Smith, and Wallace R. Roy.

1949. Phosphate fertilizer trials with oranges in Florida. I. Effects on yield, growth, and leaf and soil composition. Proc. Amer. Soc. Hort. Sci. 55:71-84.

ReUther, Walter, and C. L. CRAW FoRd.

1946. Effect of certain soil and irrigation treatments on citrus chlorosis in a calcareous soil. Soil Sci. 62:477-491.

Smith, Paul F., Walter Reuther, and Frank E. Gardner.

1949. Phosphate fertilizer trials with oranges in Florida. II. Effect on some fruit qualities. Amer. Soc. Hort. Sci. Proc. 53:85-90.

\section{TAKAHASHI, IKURO.}

1931. The effect of phosphoric acid on eitrus. Okitsu Hort. Soc. Jour. 27:18-30.

VAN DER Plank, J. E., and F. A. S. TURNER.

1936. Are our sour oranges due to lack of phosphorus? Farming in So. Africa 11:59-60.

Wallihan, E. F.

1951. The phosphorus economy of plants. Amer. Jour. Bot. (submitted for publication).

WEST, E. S.

1938. Zinc-cured mottle leaf in citrus induced by excess phosphate. Austral. Council Sci. \& Indus. Res. Jour. 11(2):182-184.

WiLLIAMs, R. F.

1948. The effect of phosphorus supply on the rates of intake of phosphorus and nitrogen upon certain aspects of phosphorus metabolism in gramineous plants. Austral. Jour. Sci. Res. Series B. Biological Seiences 1(3):333-361.

Young, T. W., and W. T. Forsee, JR.

1949. Fertilizer experiments with citrus on Davie mucky fine sand. Fla. Agr. Exp. Sta. Bul. 461. 



\section{PLATES}





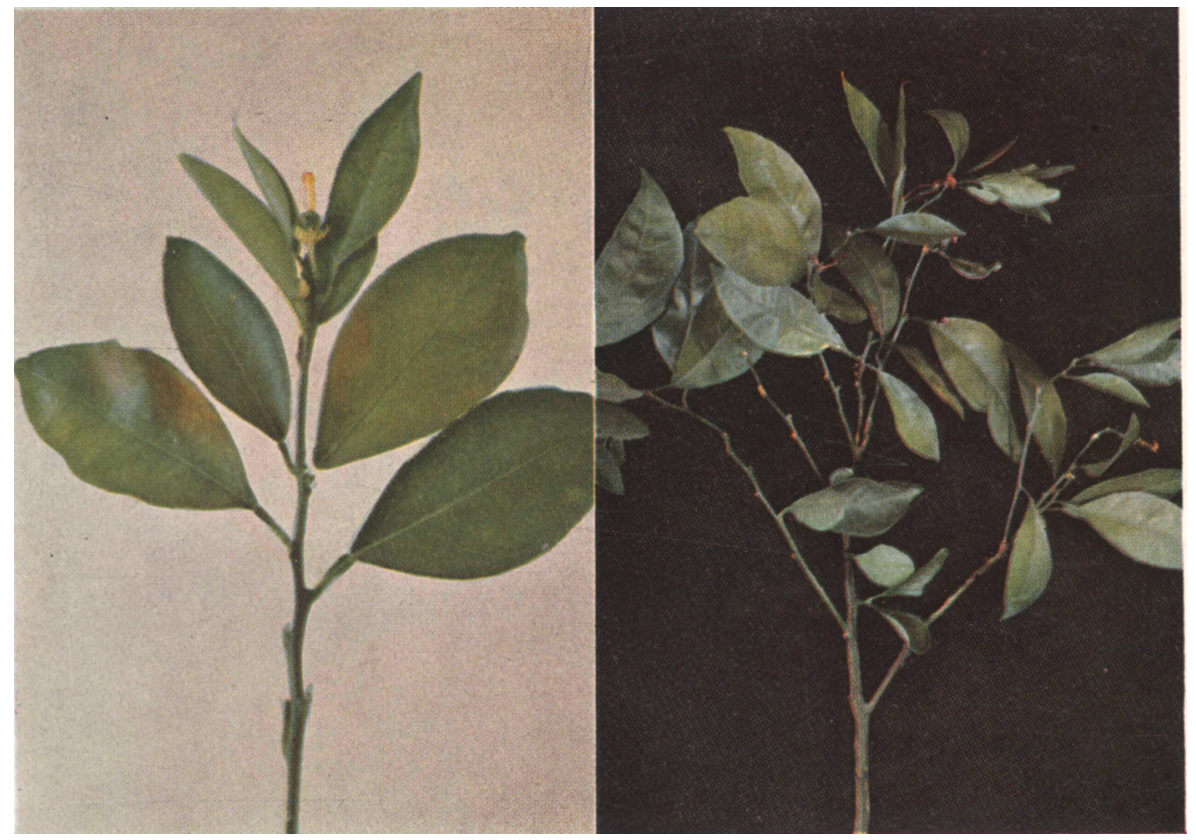

Plate 1. Effects of phosphorus deficiency on foliage. Left, shoot showing evidence of abnormal leaf abscission which occurs following bloom; bronzed dull green color of leaves. necrotic splotches and weak new growth; right, bronzed foliage, defoliation, and general appearance. 


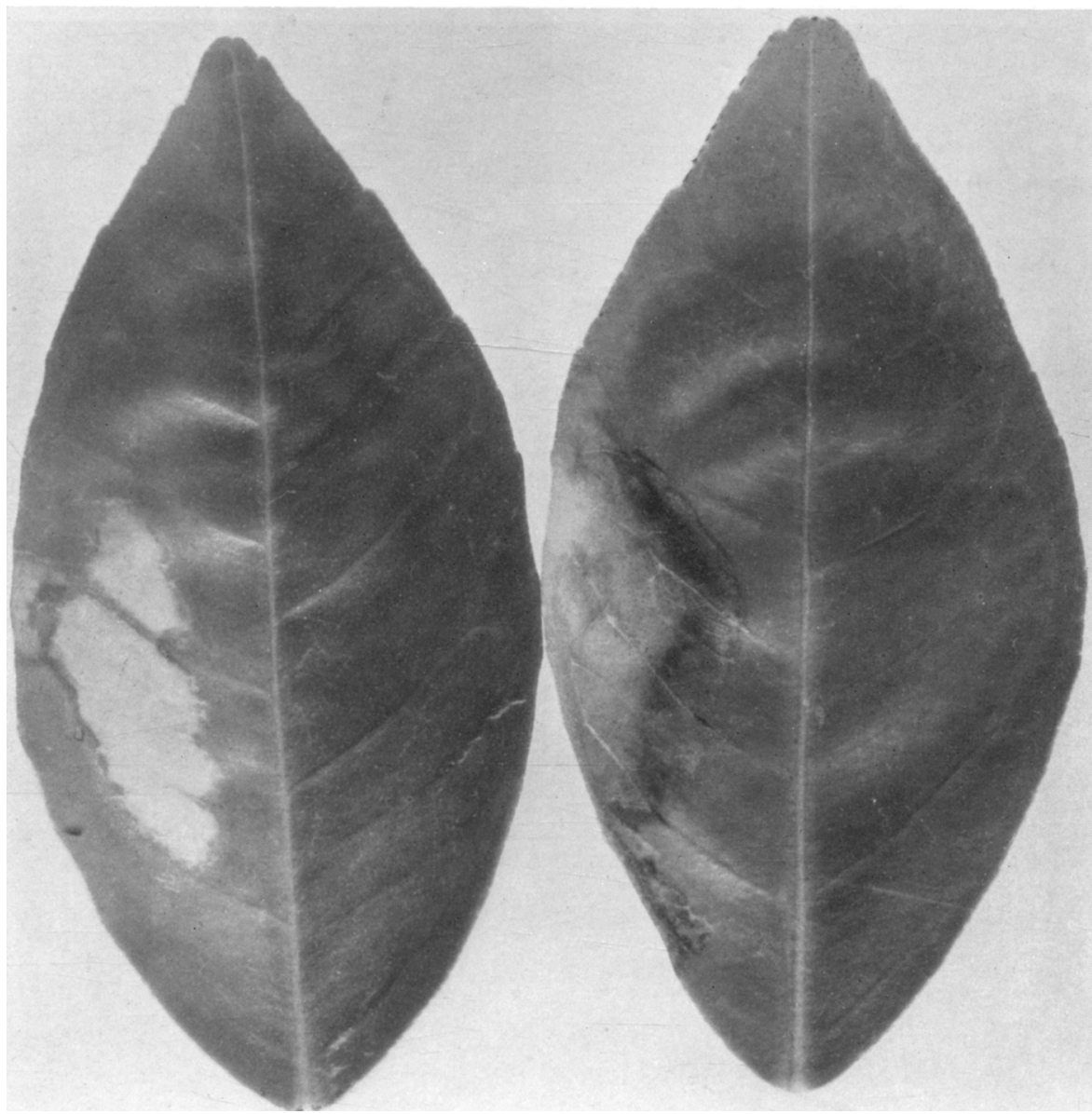

Plate 2. Typical leaves from orange tree deficient in phosphorus. Such leaves usually show a bronze color, and the burned areas or blotches may show up on the sides or tip of the leaf. Such leaves fall off soon after this burn develops. The midribs of phosphorus-deficient leaves often have a somewhat whiter cast than those of normal leaves. 


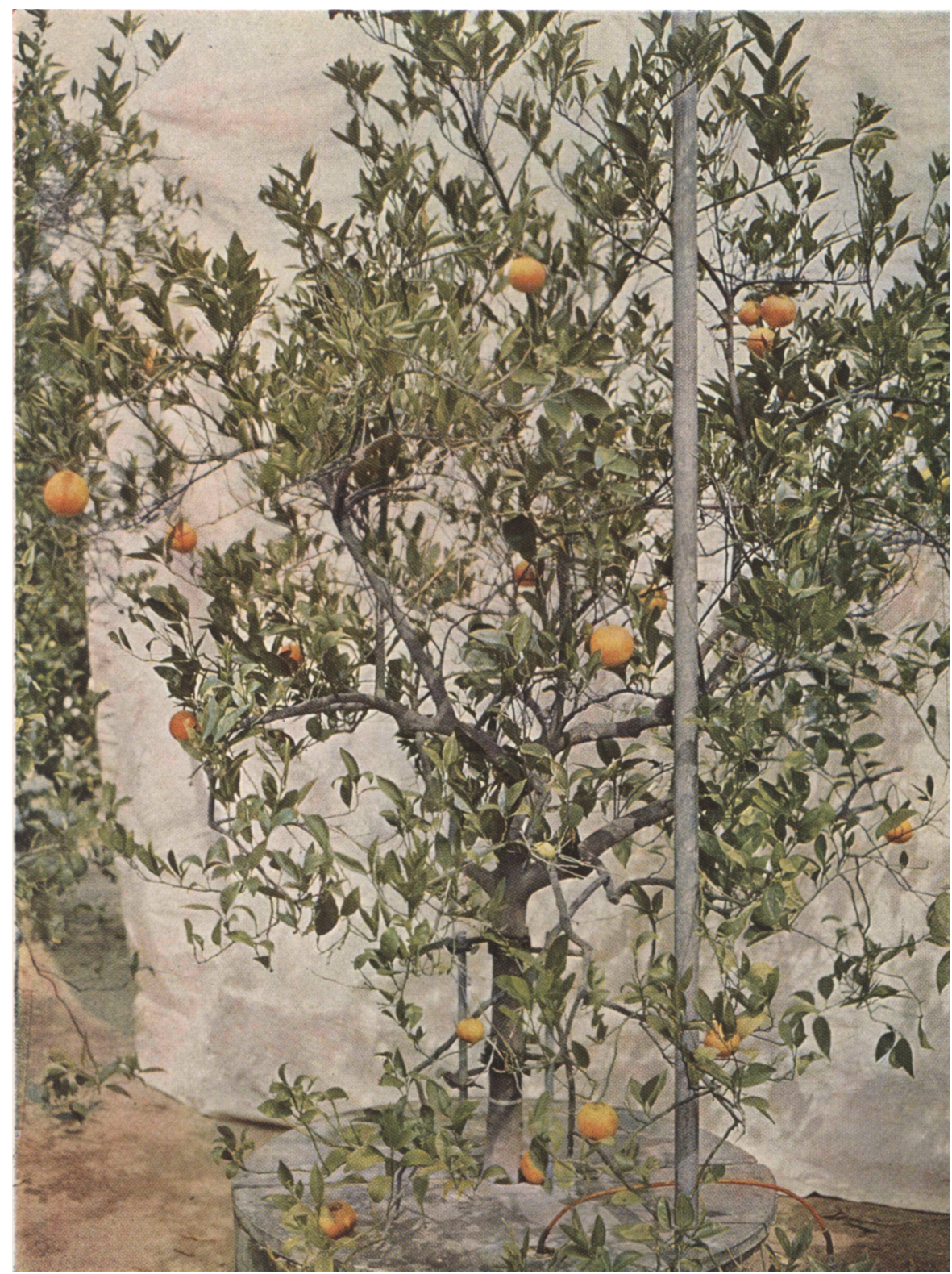

Plate 3. Navel orange tree showing effects of acute phosphorus deficiency. Note bronzed, unthrifty color of foliage, extreme open appearance, dieback, low yield, but good sizes. Tree no. 24 from former potash experiment. Healthy up until 1946 when phosphorus level decreased to 1 p.p.m. $\mathrm{PO}_{4}$. Tree became increasingly phosphate-deficient up to 1948 when a more or less constant condition became established. Photographed March, 1949. 


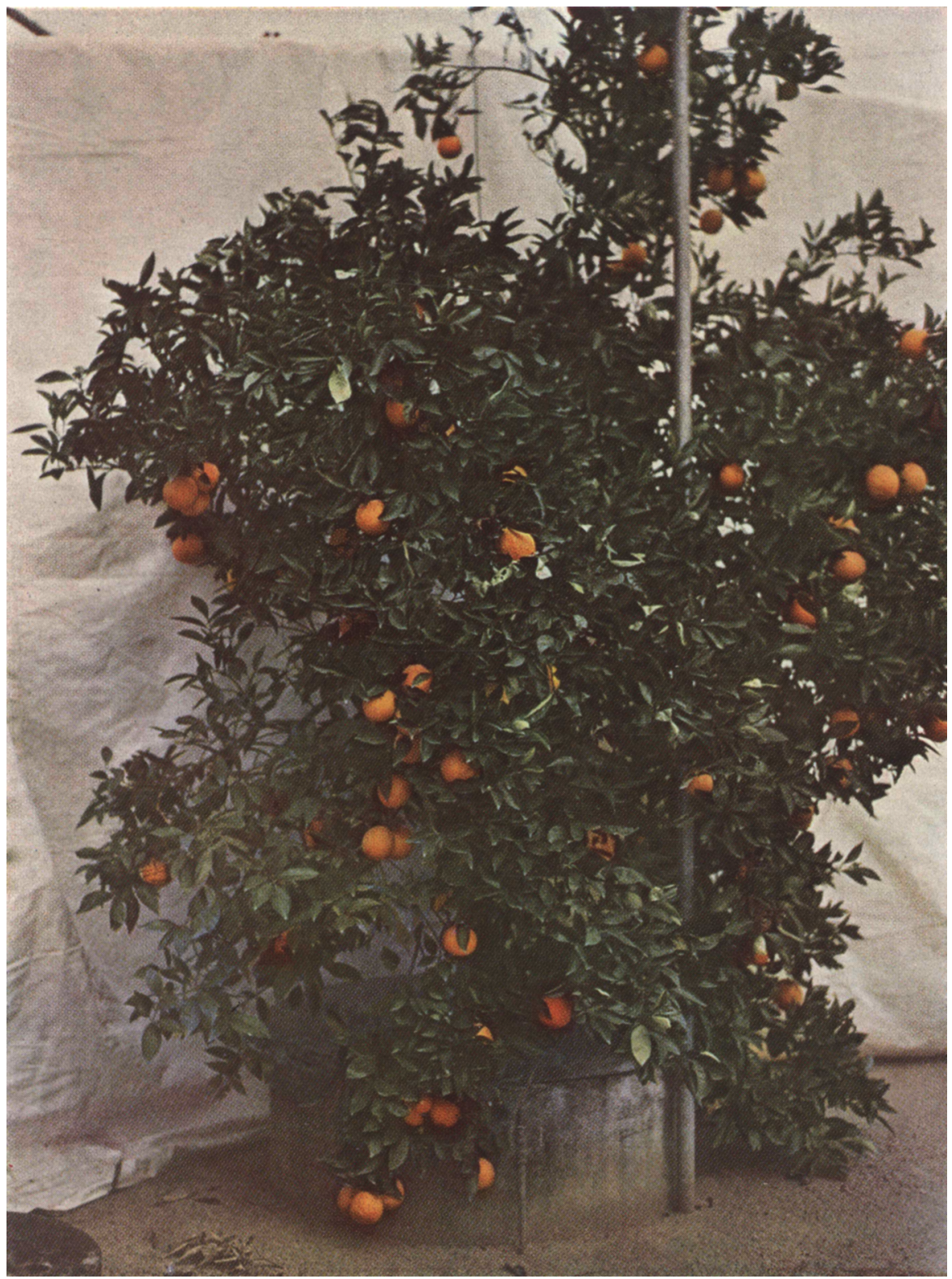

Plate 4. Navel orange tree in very earliest stage of phosphorus deficiency. At this stage there are no apparent foliage or growth manifestations. The color is deep green, yield is not impaired, but some of the fruits display characteristics such as separated centers, and thick rinds, which characterize a much larger percentage of the fruit from trees that are definitely lacking in phosphorus. Tree no. 9. Photographed March, 1949. 


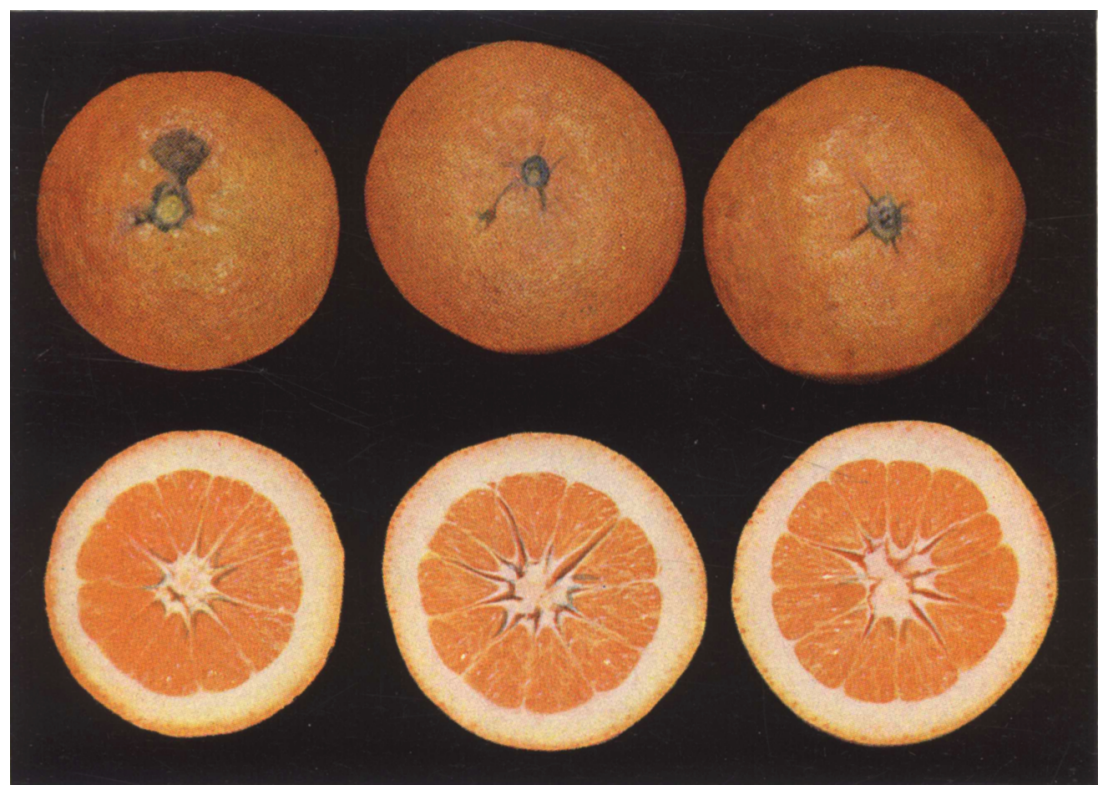

Plate 5. Exteriors and interiors of fruit from phosphorus-deficient tree. Note separation of centers and of sections, somewhat coarse juice vesicle walls, thick rinds, and somewhat misshapen character of fruit. This latter is in part due to sponginess of fruit caused by separated centers. 

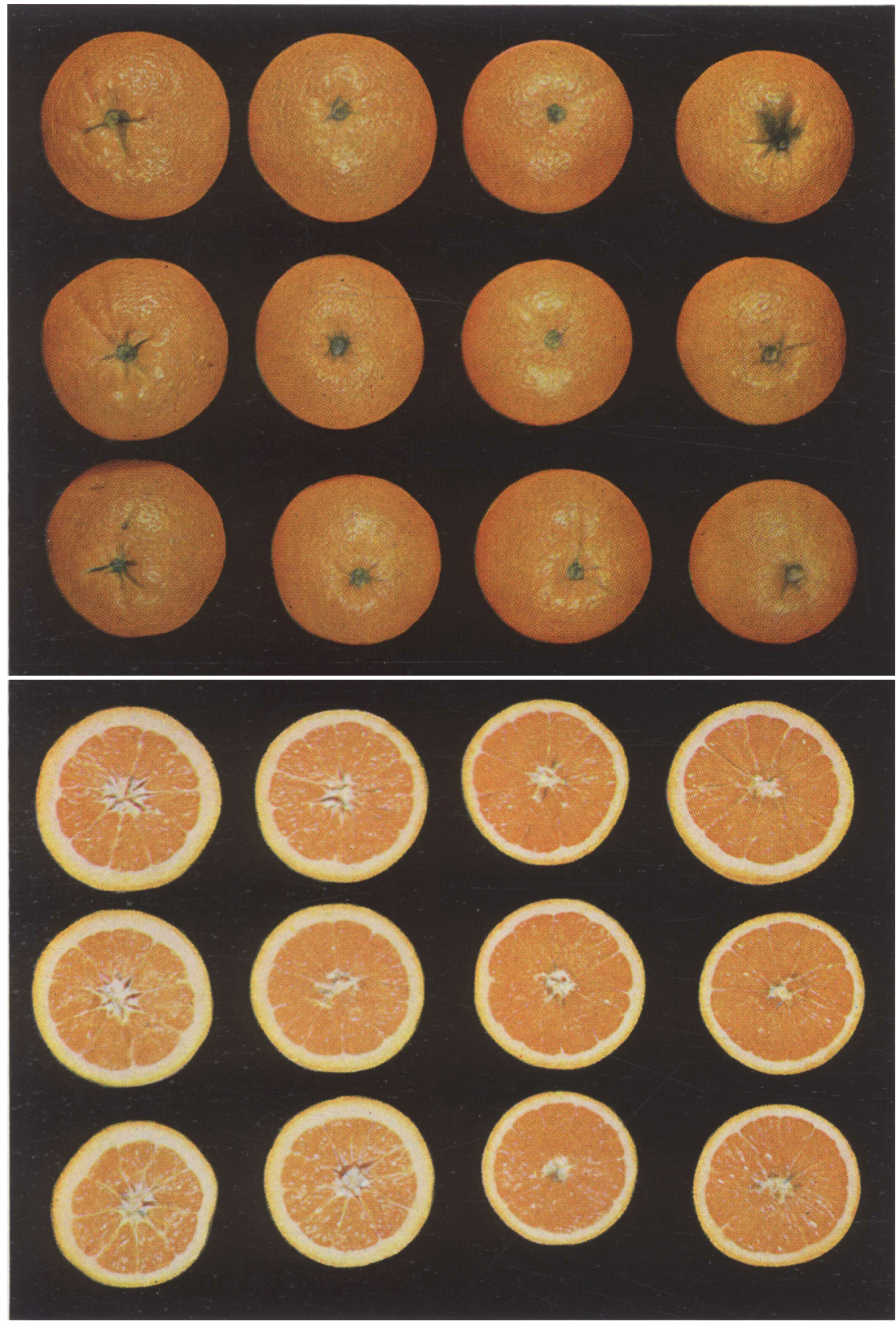

Plate 6. From left to right, effect of increasing phosphate supply on exterior and interior characteristics of fruit. Three fruits at extreme left from tree acutely deficient in phosphorus-cultures maintained at 2.5 to 3.5 p.p.m. $\mathrm{PO}_{+}$; next three fruits from trees showing no visible signs of deficiency, but characteristics of some of the fruit like those from acutely deficient trees. Next row of fruits from trees receiving 40 to 50 p.p.m. $\mathrm{PO}_{4}$, and last row from trees receiving 150 to 175 p.p.m. $\mathrm{PO}_{4}$. Note that low-phosphorus fruits are slightly deeper orange in color, sizes a little larger, fruit more misshapen and a trifle coarser, rinds thicker, and centers separated. 
The journal Hilgardia is published at irregular intervals, in volumes of about 600 pages. The number of issues per volume varies. Subscriptions are not sold. The periodical is sent as published only to libraries, or to institutions in foreign countries having publications to offer in exchange.

You may obtain a single copy of any issue free, as long as the supply lasts; please request by volume and issue number from:

\section{Publications Office \\ College of Agriculture \\ Berkeley 4, California}

The limit to nonresidents of California is 10 separate issues on a single order. A list of the issues still available will be sent on request. 